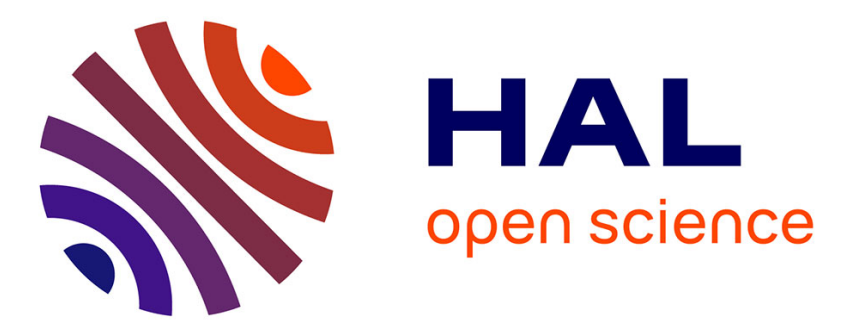

\title{
Thermodynamic characterization of the hydroxyl group on the \&\#947-alumina surface by the energy distribution function
}

Matthieu Lagauche, Kim Larmier, Elsa Jolimaître, Karin Barthelet, Céline Chizallet, Loïc Favergeon, Michèle Pijolat

\section{To cite this version:}

Matthieu Lagauche, Kim Larmier, Elsa Jolimaître, Karin Barthelet, Céline Chizallet, et al.. Thermodynamic characterization of the hydroxyl group on the \&\#947-alumina surface by the energy distribution function. Journal of Physical Chemistry C, 2017, 121 (31), pp.16770-16782. 10.1021/acs.jpcc.7b02498 . hal-01563114

\section{HAL Id: hal-01563114 \\ https://hal.science/hal-01563114}

Submitted on 23 Nov 2017

HAL is a multi-disciplinary open access archive for the deposit and dissemination of scientific research documents, whether they are published or not. The documents may come from teaching and research institutions in France or abroad, or from public or private research centers.
L'archive ouverte pluridisciplinaire HAL, est destinée au dépôt et à la diffusion de documents scientifiques de niveau recherche, publiés ou non, émanant des établissements d'enseignement et de recherche français ou étrangers, des laboratoires publics ou privés. 


\section{Thermodynamic characterization of the hydroxyls}

\section{group on the $\gamma$-alumina surface by the Energy}

\section{Distribution Function}

Matthieu Lagauche ${ }^{\dagger}$, Kim Larmier ${ }^{\dagger,}$, Elsa Jolimaitre ${ }^{*^{\dagger}}$, Karin Barthelet ${ }^{\dagger}$, Céline Chizallet ${ }^{\dagger}$, Lö̈c Favergeon ${ }^{\ddagger}$, Michèle Pijolat

${ }^{\dagger}$ IFP Energies Nouvelles, Rond-Point de l'échangeur de Solaize, BP3, 69360 Solaize, France ${ }^{\ddagger}$ Mines Saint-Etienne, LGF CNRS UMR5307, Centre SPIN, F-42023 St Etienne, France

$\S$ Department of Chemistry and Applied Biosciences, ETH Zürich, Vladimir-Prelog Weg 1-5, CH-8093, Zürich, Switzerland

KEYWORDS: $\gamma$-alumina, surface characterization, energy distribution function, surface hydroxyls, water adsorption, Density Functional Theory

\section{ABSTRACT:}

Controlling water adsorption on $\gamma$-alumina, i.e. the quantity and nature of the surface hydroxyl groups, is essential to adjust the acido/basic properties of the surface. IR and DFT studies have shown that different $\mathrm{OH}$ groups, each of them characterized by its own chemical environment and adsorption properties, can be present on the surface of $\gamma$-alumina. However, quantifying this surface heterogeneity and predicting the influence of the synthesis and activation conditions is still a challenging problem. In this paper, a detailed experimental study is conducted on a $\gamma$-alumina sample obtained by thermal decomposition of a 
commercial boehmite. Using a thermogravimetric setup, both water adsorption equilibrium and desorption kinetics were acquired in a large range of controlled experimental conditions (1 $\mathrm{Pa}<$ water partial pressures $<1400 \mathrm{~Pa} ; 100^{\circ} \mathrm{C}<$ temperatures $<600^{\circ} \mathrm{C}$ ). Based on theories developed for strongly heterogeneous surfaces, the Energy Distribution Function (EDF) of water adsorption enthalpy is evaluated. The $\mathrm{OH}$ adsorption enthalpy range of the EDF, and the experimental $\mathrm{OH}$ contents, are in good agreement with Density Functional Theory simulations, making a bridge between macroscopic and atomistic features. It is also shown that the EDF of the $\gamma$-alumina surface is a very powerful tool to predict the hydroxyl coverage as a function of the pretreatment history of the sample.

\section{INTRODUCTION}

$\gamma$-alumina is a high surface transition alumina which has wide range of applications as adsorbent and in catalysis technologies, especially as a catalysts support ${ }^{1}$. The physicochemical properties of the $\gamma$-alumina surface have therefore been the subject of many

investigations $^{2}$. The surface of alumina is composed of basic oxygen atoms, acidic lowcoordinated aluminum (Lewis acid sites) atoms, hydroxyls (dissociatively adsorbed water molecules) and physisorbed water molecules. Their relative concentrations depend essentially on synthesis conditions of alumina and its degree of hydration, itself tuned by the temperature and the water partial pressure ${ }^{3}$.

Characterization of water adsorption on the surface of $\gamma$-alumina is therefore a subject of particular concern, and this for two main reasons. First of all, the acido-basicity of the surface is strongly dependent on its degree of hydration. Hindin et al. ${ }^{4}$ have studied the hydrogenation of ethylene as a function of the activation temperature, and shown that activity of the $\gamma$ alumina catalyst is multiplied by a factor 25 when the activation temperature is raised from 
$450^{\circ} \mathrm{C}$ to $650^{\circ} \mathrm{C}$. Larmier et al..$^{5,6}$ found that water on alumina can at the same time play the role of a promoter, a poison and an inhibitor at the alumina surface, regarding its ability to catalyze isopropanol dehydration. Wischert et al. ${ }^{7}$ demonstrated the existence of an optimum in surface hydroxylation for the dissociation of methane on $\gamma$-alumina. In an industrial process, the initial degree of hydration of the surface will depend on the activation procedure (i.e. the thermal pre-treatment). Moreover, traces of water in the feed can change the degree of hydration during the course of the reaction, yielding undesirable variations of the catalyst performance. The possibility to predict the quantity - and, even better, the nature - of the hydroxyl groups present on a $\gamma$-alumina surface as a function of the operating conditions is hence of great practical interest.

The second reason is the possibility to gain some insight into the physico-chemical properties of the surface by the quantitative and qualitative characterization of the hydroxyl groups. Using Nuclear Magnetic Resonance ${ }^{8-10}$ and infra-red spectroscopy ${ }^{11-14}$ the presence of various $\mathrm{OH}$ groups have been detected on the surface of alumina, showing its strong heterogeneity $^{2,11,14}$. By performing Density Functional Theory (DFT) simulations, the link between the stretching frequencies, proton chemical shifts and the nature of the $\mathrm{OH}$ (namely the number of their aluminum neighbors, the coordination number of the aluminum they are bonded to, and the hydrogen bond network they are involved in) has been proposed ${ }^{10,15-18}$. Surprisingly, very few experimental studies focus on the measurement of water adsorption equilibrium properties. Water adsorption isotherms have been measured on $\gamma$-alumina ${ }^{19-21}$, but the data in the chemisorption region are too scarce for a detailed interpretation to be possible. Men et al. ${ }^{22}$ have measured water Temperature Programmed Desorption (TPD) on $\gamma$-alumina but not attempt to model the results was made. By coupling calorimetry and thermogravimetry, McHale et al. ${ }^{23}$ have measured the enthalpies of adsorption of water on $\gamma$ alumina as a function of coverage. The enthalpies decrease (in absolute value) logarithmically 
with coverage from $-280 \mathrm{~kJ} / \mathrm{mol}$ at $2.6 \mathrm{OH} / \mathrm{nm}^{2}$ to $-50 \mathrm{~kJ} / \mathrm{mol}$ at $15 \mathrm{OH} / \mathrm{nm}^{2}$, showing the strong heterogeneity of the adsorption sites. Others ${ }^{11,13,24,16}$ have evaluated the residual number of $\mathrm{OH}$ groups after activation under vacuum at different temperatures. However, the equilibrium hydration state also depends on the water partial pressure, which has not been investigated in detail so far.

Here, a detailed experimental study of water adsorption on $\gamma$-alumina - including equilibrium and kinetic data - is conducted via thermogravimetric analysis. Based on theoretical analysis developed for strongly heterogeneous surfaces, these data are modeled using a continuous distribution function of the water adsorption enthalpies. To our knowledge, this is the first time that such an approach is proposed for the characterization of water adsorption on the surface of alumina. These results are compared with success with Density Functional Theory calculations, allowing a connection between nanoscale features and macroscopic observations.

\section{EXPERIMENTAL SECTION AND METHODS}

\subsection{Synthesis conditions}

The $\gamma$-alumina sample was synthesized using boehmite Pural SB3 (Sasol, amount of impurities $<5$ ppm wt.) as a precursor. The partial pressure of water present in the air flow during the synthesis was about $230 \mathrm{~Pa}$ (measured by a capacitive hygrometer AlphaMoisture Model SADP). The thermal decomposition of boehmite into $\gamma$-alumina was performed in a Ushaped reactor with the following temperature program: from 20 to $120^{\circ} \mathrm{C}$ at $5^{\circ} \mathrm{C} / \mathrm{min}, 3 \mathrm{~h}$ at $120^{\circ} \mathrm{C}$ to remove most of the water, from 120 to $650^{\circ} \mathrm{C}$ at $5^{\circ} \mathrm{C} / \mathrm{min}, 6 \mathrm{~h}$ at $650^{\circ} \mathrm{C}$. The sample was then taken out of the oven and conserved at ambient atmosphere.

\subsection{Characterization of the solid}


Nitrogen physisorption isotherms at 77K were recorded on a Micrometrics ASAP 2024 physisorption analyzer. Before analysis, sample was degassed under vacuum at $350{ }^{\circ} \mathrm{C}$ for $2 \mathrm{~h}$. Specific surface area was calculated using the Brunauer-Emmett-Teller (BET) method. The studied sample exhibits a specific surface area of $228 \mathrm{~m}^{2} / \mathrm{g}$, which is a common value among commercial aluminas.

Powder X-Ray diffraction (XRD) diffractograms were recorded on a PANanytical X'PERT Pro MPD with a copper anode $(\mathrm{K} \alpha=0.15402 \mathrm{~nm})$ and a scanning rate of $0.02-0.04$ per second between $20-70^{\circ}$. The XRD pattern of the sample (Figure S1.1) confirms that we prepared a $\gamma-\mathrm{Al}_{2} \mathrm{O}_{3}$ (ICDD 00-050-0741).

Transmission Electronic Microscopy (TEM) has been performed using a (JEM-2100, JEOL, Japan) to evaluate the morphology of the sample (Figure S1.2). Samples were prepared by drying a drop of diluted alumina powder in ethanol on copper grids coated by amorphous carbon. The particles aggregate together into an oblong-shape form, making it difficult to determine precisely their morphology and their size (around $10 \mathrm{~nm}$ ).

\subsection{Thermogravimetric measurements}

To perform water adsorption experiments, a symmetric thermogravimetric analyzer SETARAM TAG-B12 was used. It is equipped with two furnaces: one for the studied sample placed in a quartz crucible, one used as a reference with an empty quartz crucible. This configuration allows to reduce drastically thermal gap phenomena and Archimides principle variations between the furnaces. As such, no correction is needed. As shown on Figure 1, the water content of the gases flowing through the unit can be tuned between 1 and $1400 \mathrm{~Pa}$. 
- The lower partial water partial pressure, $1 \mathrm{~Pa}$, was obtained by installing gas dryers (i.e. fixed beds of $3 \mathrm{~A}$ zeolite) on the inlet and outlet (to prevent water counterdiffusion from ambient air) of the unit.

- A calibrated water content gas bottle can deliver a gas at water partial pressure of 20 $\mathrm{Pa}$.

- For the highest partial pressure, a saturation device was used. The maximum partial pressure of water is $1400 \mathrm{~Pa}$ (to avoid condensation in the lines). Intermediate partial pressures are obtained by dilution with dry gas.

For all experiments, the water content is measured by a hygrometer AlphaMoisture SADP.

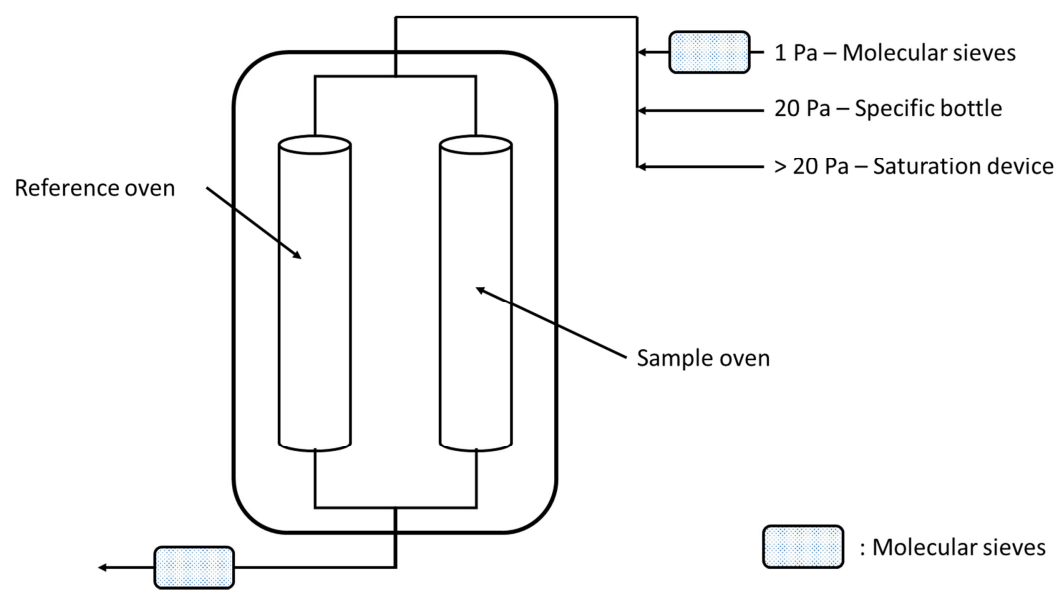

Figure 1: Schematic representation of the TAG-B12 thermogravimetric unit.

Sorption experiments include three different protocols, using the device previously described: classical TPD, interrupted TPD, adsorption experiments. For all experiments, about $70 \mathrm{mg}$ of sample was used, and the temperature increase or decrease rate is kept at $5^{\circ} \mathrm{C} / \mathrm{min}$.

- $\quad$ Temperature Programmed Desorption (TPD) 
Classical TPD: The sample is first pretreated in the thermogravimetric unit: $10 \mathrm{~h}$ at $30^{\circ} \mathrm{C}$ to remove most of the physisorbed water followed by $4 \mathrm{~h}$ at $100^{\circ} \mathrm{C}$. After pretreatment, the temperature is raised to $600^{\circ} \mathrm{C}$ at $5^{\circ} \mathrm{C} / \mathrm{min}$ and the mass variation due to water desorption is recorded. All the TPDs were performed at a partial pressure of water of $1 \mathrm{~Pa}$.

Interrupted TPD: After pretreatment (same procedure as for classical TPDs), the temperature is raised step by step from 100 to $600^{\circ} \mathrm{C}$ in increments of $100^{\circ} \mathrm{C}$. The desorption kinetic varies with temperature and water partial pressure, the duration of the temperature plateau was therefore adapted so as to record the signal until the mass was considered as stabilized.

- Adsorption experiments

The sample was first heated at $600^{\circ} \mathrm{C}$ with a fixed partial pressure of water (between 1 and $1400 \mathrm{~Pa}$ ). Temperature steps are then applied, going down from 600 to $100^{\circ} \mathrm{C}$, for 5 h.

For interrupted TPDs and adsorption experiments, a final step of $4 \mathrm{~h}$ at $600^{\circ} \mathrm{C}$ and $1 \mathrm{~Pa}$ of water is always applied, in order to evaluate the reference mass of the sample.

This notion of reference mass was introduced because there is no way, by thermogravimetric measurements, to evaluate the "absolute" mass $m_{a b s}$ of the sample, that is to say its mass in its completely dehydrated state (if such a state exists), without risking a phase transition from $\gamma$ - to $\delta$ - or even $\theta$-alumina. This issue is illustrated on Figure 2 . The raw measurement in a TPD experiment are the initial mass $m_{i}$ and the mass variation $\Delta m$ as a function of time. When the temperature is raised, the mass approaches the absolute mass of the alumina sample, but also the temperature of phase transition from $\gamma$ - to $\delta$-alumina. The reference mass $m_{r e f}$ is therefore the one measured under the most dehydrating state obtainable with no risk of phase transition, i.e. $600^{\circ} \mathrm{C}\left(50^{\circ} \mathrm{C}\right.$ under the temperature selected for the thermal 
decomposition of boehmite), $1 \mathrm{~Pa}$ of water (the lower partial pressure obtainable with our experimental device) and $3 \mathrm{~h}$ (time necessary to stabilize the mass signal).

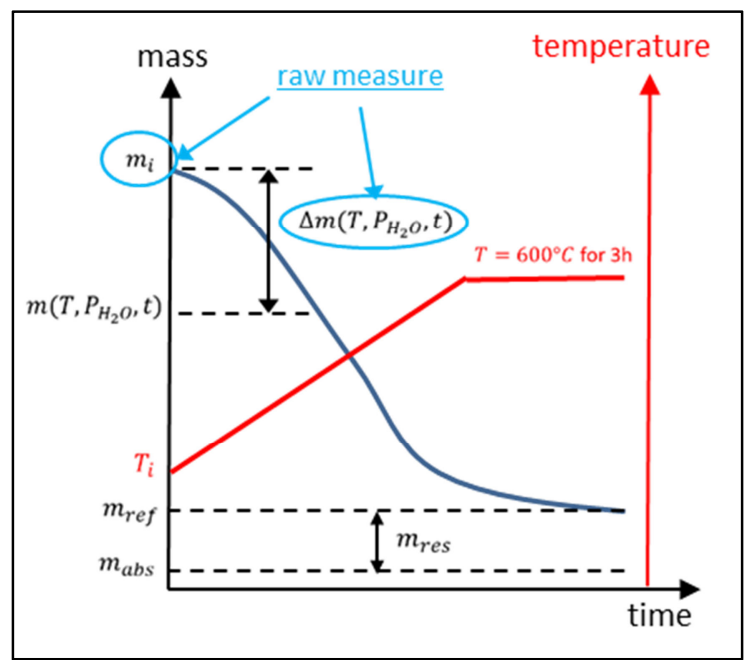

Figure 2: Reference and absolute mass for TPD experiments.

The $\mathrm{OH}$ concentration on the surface with respect to the reference state is evaluated using the expression:

$\mathrm{q}^{r e f}\left(T, P_{\mathrm{H}_{2} \mathrm{O}}, t\right)=\frac{m\left(T, P_{\mathrm{H}_{2} \mathrm{O}}, t\right)-m_{r e f}}{m_{r e f}}$

with:

$\mathrm{q}^{\text {ref }}$ : the $\mathrm{OH}$ concentration with respect to the reference state $(\mathrm{g} / \mathrm{g})$

$m_{r e f}:$ the mass at the reference state $(\mathrm{g})$

$m\left(T, P_{\mathrm{H}_{2} \mathrm{O}}, t\right)$ : the mass for a given operating condition $(\mathrm{g})$

Note that the absolute masses are calculated from the raw data using the following equation:

$m=m_{i}-\Delta m$

Eq. (2)

To express the concentration in $\mathrm{OH} / \mathrm{nm}^{2}$, the formula is: 
$\mathrm{q}^{r e f}\left(\mathrm{OH} / \mathrm{nm}^{2}\right)=\mathrm{q}^{r e f}(\mathrm{~g} / \mathrm{g}) \frac{N_{A} \times 2}{M_{\mathrm{H}_{2}} \times S_{B E T} \times 10^{18}}$

with:

$N_{A}$ : Avogadro number $\left(\mathrm{mol}^{-1}\right)$

$M_{\mathrm{H}_{2} \mathrm{O}}:$ molecular mass of water $(\mathrm{g} / \mathrm{mol})$

$S_{B E T}:$ specific surface area of the sample $\left(\mathrm{m}^{2} / \mathrm{g}\right)$

To form a water molecule, two hydroxyls are needed, explaining the presence of a factor 2 at the numerator of eq 3. In this paper, the experimental thermogravimetric data are compared with DFT simulations, which supply absolute $\mathrm{OH}$ concentrations. It is thus necessary to establish the relation between these two quantities. We show in Supporting Information S2 that with a good level of approximation, the absolute surface $\mathrm{OH}$ concentration $\mathrm{q}^{\text {abs }}$ is given by eq 4:

$\mathrm{q}^{a b s}\left(T, P_{\mathrm{H}_{2} \mathrm{O}}, t\right)=\mathrm{q}^{r e f}\left(T, P_{\mathrm{H}_{2} \mathrm{O}}, t\right)+\mathrm{q}^{r e s}$

where $\mathrm{q}^{\text {res }}$ is the absolute residual surface concentration of $\mathrm{OH}$ groups. This means that the absolute concentration can be easily evaluated from the thermogravimetric data provided the residual $\mathrm{OH}$ concentration is known. In this paper, the residual $\mathrm{OH}$ concentration will be measured by chimiometry (see section 2.4.) and it will be shown that its mass is indeed negligible compared to that of the dehydrated sample.

From eq. 4, and knowing that the residual concentration is a constant, one can also write:

$\frac{\mathrm{dq}^{a b s}\left(T, P_{\mathrm{H}_{2} O}, t\right)}{d t} \approx \frac{\mathrm{dq}^{r e f}\left(T, P_{\mathrm{H}_{2} O}, t\right)}{d t}$ Eq. (5)

The desorption rates based on the absolute or the reference mass are hence equivalent. The energy distribution functions (EDF) can hence be directly estimated from the TPD data (without taking into account the residual hydroxyls). 


\section{Evaluation of energy distribution functions from TPD data}

As seen previously, the surface of $\gamma$-alumina is extremely heterogeneous, that is to say it is expected to be composed of adsorption sites of different chemical nature characterized by a whole range of water adsorption enthalpies. The solution proposed in the literature ${ }^{25,26}$ to represent such a surface is the Energy Distribution Function (EDF), a continuous function that relates the relative frequencies (existence probabilities) of surface sites associated to a given adsorption enthalpy:

$$
f\left(\Delta_{a d s} H\right)=\frac{q_{s}\left(\Delta_{a d s} H\right)}{q_{s, t}}
$$

Where $q_{s}$ is the $\mathrm{OH}$ saturation concentration related to a given adsorption enthalpy $\Delta_{a d s} H$, and $q_{s, t}$ is the total saturation concentration of the surface. As the EDF will be estimated from TPD experiments, the concentrations in eq. 6 (and in the rest of this section) are relative to the reference mass of the sample. For a given EDF function, the quantities adsorbed on an heterogeneous surface at equilibrium can be calculated using the following relation:

$$
\theta_{t}\left(T, P_{H_{2} O}\right)=\int_{\Omega} \theta\left(T, P_{H_{2} O}, \Delta_{a d s} H\right) f\left(\Delta_{a d s} H\right) d \Delta_{a d s} H
$$

where $\theta_{t}=q_{t} / q_{s, t}$ is the total fractional coverage, $\theta=q\left(\Delta_{a d s} H\right) / q_{s}\left(\Delta_{a d s} H\right)$ is the fractional coverage on a site of adsorption enthalpy $\Delta_{a d s} H$ and $\Omega$ is the domain of adsorption enthalpy considered i.e. $\Omega=\left[\Delta_{\text {ads }} \mathrm{H}_{\text {min }} ; \Delta_{\text {ads }} \mathrm{H}_{\text {,max }}\right]$. Eq. 7 simply expresses that the total fractional coverage is the sum of the fractional coverage of each site, balanced by its existence probability. Consequently, the adsorption/desorption kinetic is given by eq. 8 :

$$
\frac{d \theta_{t}\left(T, P_{\mathrm{H}_{2} \mathrm{O}}\right)}{d t}=\int_{\Omega} \frac{d \theta\left(T, P_{\mathrm{H}_{2} O}, \Delta_{a d s} H\right)}{d t} f\left(\Delta_{a d s} H\right) d \Delta_{a d s} H
$$

Thus, the EDF is essentially a mathematical representation of the complex interaction between a heterogeneous surface and a given adsorbate. It is a very powerful tool, because it 
contains intrinsically all the information required to simulate the equilibrium state and the desorption kinetic of the surface for any experimental condition.

The drawback of this theory is the difficulty to evaluate the EDF from experimental data. In the literature, EDF estimation procedures are proposed based on either kinetic (i.e. TPD) or equilibrium data. ${ }^{25}$ In this work, the EDF for water on our $\gamma$-alumina sample will be evaluated from both classical and so called "interrupted" TPD experiments. Secondly, the EDF has to be validated using independent experiments, i.e. not the same set as used in the estimation step. In our case, adsorption experiments will be used.

\section{Adsorption/desorption on each site}

To describe the properties of a heterogeneous surface, it is first necessary to define an adsorption model for each individual site. In this work, the theoretical framework to extract the EDF is based on the kinetic derivation of the Langmuir adsorption isotherm. Water adsorption on $\gamma$-alumina can be considered as a chemical reaction between a water molecule and an adsorption site s:

$$
\mathrm{H}_{2} \mathrm{O}+\mathrm{S} \underset{k_{d}}{\stackrel{k_{a}}{\rightleftarrows}} H_{2} \mathrm{O}-\mathrm{S}
$$

where $\mathrm{H}_{2} \mathrm{O}-\mathrm{S}$ is the water molecule in the adsorbed state. If water encounters dissociative chemisorption, as it is the case for $\gamma$-alumina, one should rigorously write:

$$
\mathrm{H}_{2} \mathrm{O}+s_{1}+s_{2}-\mathrm{O} \underset{k_{d}}{\stackrel{k_{a}}{\rightleftarrows}} S_{1} \mathrm{OH}+s_{2} \mathrm{OH}
$$

where $s_{1}$ is the hydroxyl acceptor site and $s_{2}-\mathrm{O}$ the proton acceptor site. As each water molecule needs both types of sites in order to chemisorb, the two adsorption sites can be gathered and considered as a unique adsorption site: 


$$
\mathrm{H}_{2} \mathrm{O}+\left(s_{1} s_{2}\right) \underset{k_{d}}{\stackrel{k_{a}}{\rightleftarrows}}\left(s_{1} s_{2}\right)-H_{2} \mathrm{O}
$$

Thus dissociative and non-dissociative adsorption can then be represented by the same equation. Assuming that there is no interaction between adsorbed molecules, then adsorption on each site can be modeled with the Langmuir isotherm:

$$
\theta=\frac{K \cdot \frac{P_{\mathrm{H}_{2} \mathrm{O}}}{P^{\circ}}}{1+K \cdot \frac{P_{\mathrm{H}_{2} \mathrm{O}}}{P^{\circ}}}
$$

where:

$$
K=\frac{k_{a}}{k_{d}}=K_{0} \exp \left(-\frac{\Delta_{a d s} H}{R T}\right)
$$

with:

$$
K_{0}=\exp \left(\Delta_{a d s} S / R\right)
$$

and $\Delta_{a d s} H$, the (negative) adsorption enthalpy and $\Delta_{a d s} S$ the adsorption entropy.

Equation 13 shows that for adsorbates having strong interactions with the surface sites (i.e. high values of $\mathrm{K}$ ), as is the case for water on alumina, adsorption is much faster than desorption. It can therefore be assumed (as will be confirmed in section 3.3) that adsorption experiments yield equilibrium data.

However, for TPD experiments where water partial pressure is very low, the adsorption rate can be neglected and the desorption rate for a given site is:

$$
r_{d}=\frac{d \theta}{d t}=-k_{d} \theta
$$

If the activation energy for adsorption is negligible, then the activation energy for desorption is equal to the opposite of the enthalpy of adsorption:

$$
k_{d}=A_{d} \exp \left(-\frac{\Delta_{a d s} H}{R T}\right)
$$


According to the Transition State Theory (TST), the pre-exponential factor $A_{d}$ should be a function of temperature, entropy of activation, and of Boltzmann's and Planck's constants. ${ }^{27}$ However, for different reasons extensively discussed in the literature, ${ }^{25,28,29}$ a linear relationship - not predicted by the TST - is often found between the logarithm of the preexponential factor and the enthalpy of adsorption, called the "compensation effect". It is therefore necessary to determine the pre-exponential factor - and its relationship with $\Delta_{a d s} H$ for each adsorbant/adsorbate couple.

In a TPD experiment, the solid is heated from an initial temperature $T_{i}$ to a final temperature $\mathrm{T}_{\mathrm{f}}$ with a constant heating rate $\beta$. The desorption rate can be evaluated using equations 15 and 16:

$$
\frac{d \theta}{d t}=\beta \frac{d \theta}{d T}=-A_{d}\left(\Delta_{a d s} H\right) \exp \left(-\frac{\Delta_{a d s} H}{R T}\right) \theta
$$

Integration between $\mathrm{T}_{\mathrm{i}}$ and $\mathrm{T}_{\mathrm{f}}$ yields:

$$
\theta=\exp \left[-\frac{1}{\beta} \int_{T_{i}}^{T_{f}} A_{d}\left(\Delta_{a d s} H\right) \exp \left(-\frac{\Delta_{a d s} H}{R T}\right) d T\right]
$$

Eq. 18 does not have an analytical solution. The following expression has been proposed ${ }^{26}$ as a good approximation when $T_{i}$ is small :

$$
\theta=\exp \left[\frac{-A_{d}\left(\Delta_{a d s} H\right) R T^{2}}{\beta \Delta_{a d s} H} \cdot \frac{1}{\sqrt{1+2 R T / \Delta_{a d s} H}} \exp \left(\frac{-\Delta_{a d s} H}{R T}\right)\right]
$$

\section{Extension to the whole heterogeneous surfaces}

Once the behavior of each individual site has been modeled, the kinetic properties of the surface as a whole can be assessed. Combining equations 8 and 17 gives the total desorption rate $r_{d, t}$ that can be easily extracted from the experimental thermogravimetric signal: 


$$
r_{d, t}=\frac{d \theta_{t}\left(T, P_{H_{2} O} O\right.}{d t}=\int_{\Omega}-A_{d} \exp \left(\frac{-\Delta_{a d s} H}{R T}\right) \theta\left(\Delta_{a d s} H, T, P_{H_{2} O}\right) f\left(\Delta_{a d s} H\right) d \Delta_{a d s} H \quad \text { Eq. (20) }
$$

Inversion of this equation in order to evaluate $f\left(\Delta_{a d s} H\right)$ from TPD desorption kinetic has been shown to be a numerically ill-posed problem ${ }^{26,30-32}$ i.e. very different EDF can yield nearly similar kinetics. Getting around this difficulty has been the object of considerable studies. $^{28}$

In this work, the TPD experiments will be interpreted using the approach proposed by Barrie $^{26}$, who recommends an original methodology to estimate the kinetic pre-exponential term $A_{d}$ as a function of $\Delta_{a d s} H$. We will not go through the detailed derivation of the equations. Interested readers are invited to consult Barrie's original paper. ${ }^{26}$ However, a summary of the main hypotheses and of the resulting equations is given below.

One of the major hypothesis is the condensation approximation (CA), which supposes that the fractional coverage of a given site is a step function, that is to say:

$$
\theta\left(\Delta_{a d s} H, T\right)=0 \text { for }-\Delta_{a d s} H<-\Delta_{a d s} H^{*} \text { and } \theta\left(\Delta_{a d s} H, T\right)=1 \text { for }-\Delta_{a d s} H>-\Delta_{a d s} H^{*}
$$

At a given temperature, all the sites with an adsorption enthalpy inferior to the critical value $\Delta_{a d s} H^{*}$ (in absolute values) are empty while all the other sites are saturated. Next, the relation between the critical enthalpy and the temperature has to be established. Barrie supposes that the critical enthalpy is the one that averages the desorption kinetics, which gives: ${ }^{26}$

$$
\left(\frac{\Delta_{a d s} H^{*}}{R T}-0.368\right) \exp \left(\frac{\Delta_{a d s} H^{*}}{R T}-0.368\right)=\frac{A_{d}\left(\Delta_{a d s} H^{*}\right) T}{\beta}
$$

If $A_{d}$ does not vary with $\Delta_{a d s} H^{*}$, then the EDF can be calculated using:

$$
f\left(\Delta_{a d s} H^{*}\right)=\frac{1}{\beta} \frac{r_{d, t}(T)}{d\left(\Delta_{a d s} H^{*}\right) / d T}
$$


with:

$$
\frac{d \Delta_{a d s} H^{*}}{d T}=R\left(\frac{x^{* 2}+1.632 x^{*}-0.368}{x^{*}+0.632}\right)
$$

where $x^{*}=\frac{\Delta_{a d s} H^{*}}{R T}$.

Eq. 23 shows that the EDF can be derived from experimental desorption kinetics (i.e. $r_{d, t}(T)$ ). For a given value of $A_{d}, \Delta_{a d s} H^{*}$ can be evaluated at each temperature using eq. 22 . Then $d \Delta_{a d s} H^{*} / d T$ is calculated using eq. 24. Substitution of this function into eq. 23 directly gives the EDF.

If $A_{d}$ varies with the adsorption enthalpy, estimation of the EDF is more complicated. To begin with, it requires complementary TPD experiments, called interrupted TPD. The solid is first heated with a heating rate $\beta$ to a given temperature $T_{\text {int }}$. The temperature is then kept at that value for a chosen duration, before the sample is once again heated until the next interruption. From these interrupted TPD, the evolution of $A_{d}$ with $\Delta_{a d s} H^{*}$ can be evaluated.

The procedure is schematized on Figure 3:

- $A_{d}$ is fixed at a guess value.

- The EDF is calculated from classical TPD experiments.

- The fractional coverage at the beginning of isothermal step is calculated, as well as the evolution of the fractional coverage during the temperature plateau at $T_{\text {int }}$. During the interruption, the temperature is constant, and the total desorption kinetic can be calculated using eq. 20 with the kinetic of each individual adsorption site being:

$$
\theta\left(\Delta_{a d s} H^{*}, t\right)=\theta_{\text {int }}\left(\Delta_{a d s} H^{*}\right) \exp \left[-k_{d}\left(A_{d}, \Delta_{a d s} H^{*}\right) \cdot t\right]
$$

where $\theta_{\text {int }}\left(\Delta_{a d s} H^{*}\right)$, the fractional coverage of an individual site at the beginning of the isothermal period, can be calculated using eq. 19. 
- Finally, the optimal value of $A_{d}$ (the one that minimizes the difference between the experimental and simulated desorption curves) is determined.

- This procedure is repeated for different values of $T_{i n t}$. The value of $\Delta_{a d s} H^{*}$ can be calculated for each $T_{i n t}$, yielding the evolution of $A_{d}$ with $\Delta_{a d s} H^{*}$.

Once the function relating $A_{d}$ with $\Delta_{a d s} H^{*}$ is known, the EDF can be estimated from a classical TPD desorption kinetic:

$$
f\left(\Delta_{a d s} H^{*}\right)=\frac{r_{d, t}}{\int_{\Omega} r_{d}\left(\Delta_{a d s} H^{*}\right) d \Delta_{a d s} H^{*}}
$$

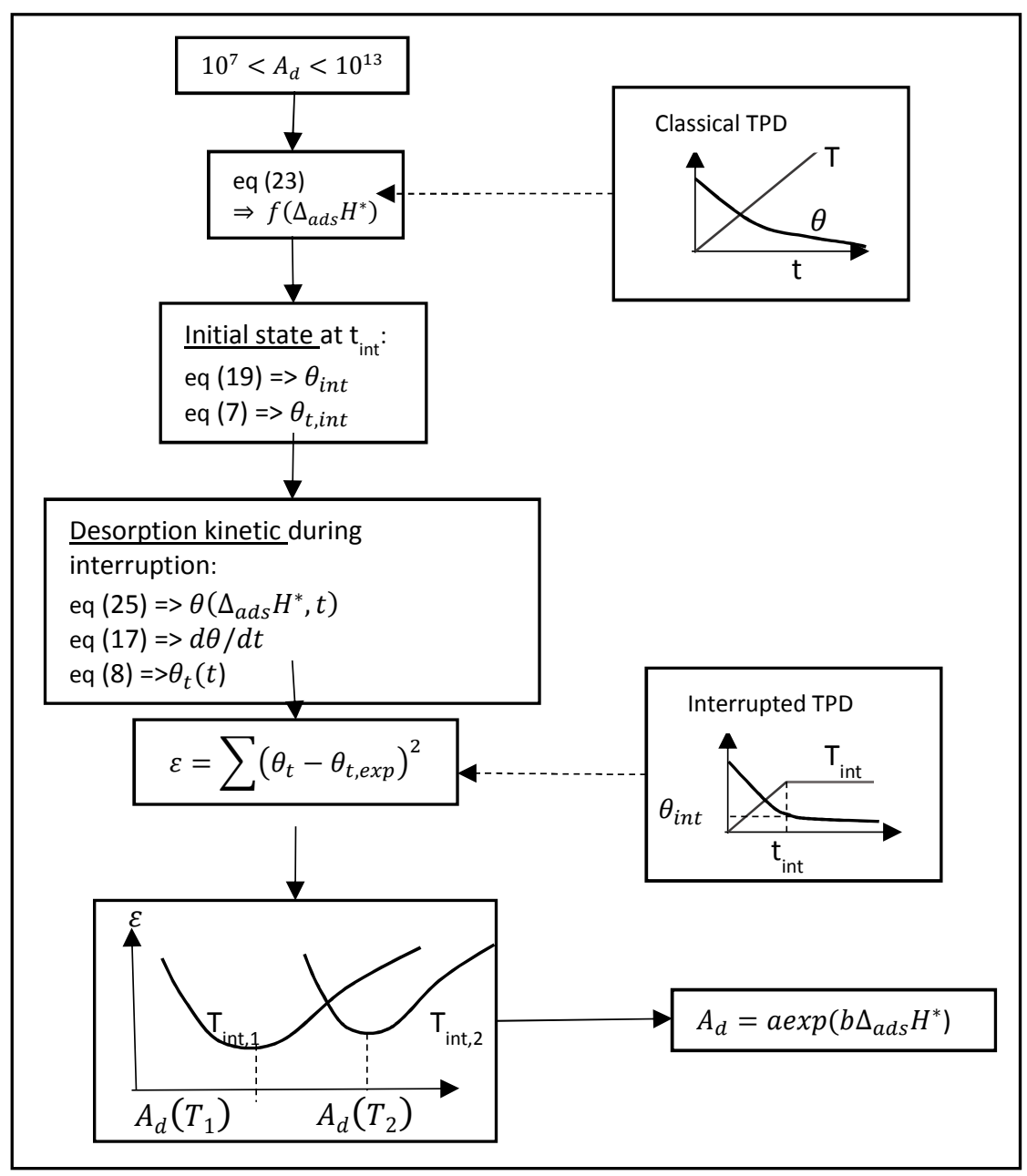

Figure 3: Representation of the procedure to evaluate $A_{d}$ 


\subsection{Determination of the $\mathrm{OH}$ content in the reference state}

As seen in section 2.3., the hydroxyls that are still adsorbed on the surface after a heat treatment at $600^{\circ} \mathrm{C}$ cannot be quantified by the thermogravimetric analysis. Hence, in order to calculate the absolute coverage of surface $\mathrm{OH}$ groups $\mathrm{q}^{a b s}$ (in $\mathrm{OH}$ per $\mathrm{nm}^{2}$ ), we measured the residual number of $\mathrm{OH}$ groups on the surface of the $\gamma$-alumina $q^{\text {res }}$ in the reference state by chimiometry $^{33}$. To do so, the $\gamma$-alumina sample was treated under vacuum $\left(10^{-4} \mathrm{mbar}\right.$, or $10^{-2}$ Pa) at $600{ }^{\circ} \mathrm{C}$ for 4 hours (ramp $5{ }^{\circ} \mathrm{C} / \mathrm{min}$ ). After cooling down to room temperature under dynamic vacuum, the sample was transferred into a glovebox (Ar). For the titration, $65.3 \mathrm{mg}$ of sample were introduced into an air-tight J-Young tube, along with $30 \mathrm{mg}$ of dibenzylmagnesium $\left(\mathrm{Bn}_{2} \mathrm{Mg}(\mathrm{thf})_{2}\right)$ (homemade, $87 \mu \mathrm{mol}$, in excess), $14.7 \mathrm{mg}$ of ferrocene (Sigma-Aldrich, sublimed before use) as an internal standard $(79.0 \mu \mathrm{mol})$ and $1 \mathrm{~mL}$ of deuterated benzene $\mathrm{C}_{6} \mathrm{D}_{6}$ (CortecNet, vacuum distilled from purple $\mathrm{Na}^{0} /$ benzophenone before use). The tube is vigorously stirred for several minutes in order to dissolve all the components and react the alumina surface with the dibenzylmagnesium, according to the titration equation 27:

$$
\mathrm{Al}-\mathrm{OH}+\mathrm{Bn}_{2} \mathrm{Mg}(\text { thf })_{2}=\mathrm{Al}-\mathrm{O}-\mathrm{MgBn}+\text { Toluene }
$$

After reaction, a ${ }^{1} \mathrm{H}$ NMR spectrum is recorded (Brucker $250 \mathrm{MHz}$ spectrometer) with a recycling delay $d_{1}$ of $60 \mathrm{~s}$ to ensure a quantitative measurement. Integration of the toluene signal (area 0.167, $2.6 \mathrm{ppm}, 3 \mathrm{H}$ ) and ferrocene signal (area 1.00, 4.6 ppm, 10H) allows access to the amount of toluene formed and hence the number of surface $\mathrm{OH}$ groups $\mathrm{q}^{\text {res }}$. The calculation yields $\mathrm{q}^{\text {ref }}=1.7 \mathrm{OH} . \mathrm{nm}^{-2}$ or $6 \mathrm{mg} / \mathrm{g}$. The hydroxyls represent therefore less than $1 \%$ of sample mass and the approximation corresponding to eq. 4 is therefore fully justified.

The preparation procedure used for this experiment should yield a surface hydration state close to the reference state defined in section 2.3., although it was prepared under a lower 
pressure $\left(10^{-2} \mathrm{~Pa}\right.$ instead of $\left.1 \mathrm{~Pa}\right)$. Nonetheless, note that the $\mathrm{OH}$ coverage does not significantly depend on the water pressure for temperatures higher than $400{ }^{\circ} \mathrm{C}$ and water pressures lower than $100 \mathrm{~Pa}$ (see later, Figure 10 and Figure 12). Hence, we calculate the absolute $\mathrm{OH}$ coverage using eq. 4.

\subsection{DFT calculations}

Calculation settings. The hydrated surface of the $\gamma$-alumina has been modeled by periodic DFT, with the PBE exchange correlation functional ${ }^{34}$, and dispersion corrections at the D2 level, ${ }^{35}$ using the VASP ${ }^{36,37}$ code, with a cutoff energy of $500 \mathrm{eV}$ (PAW pseudopotentials ${ }^{38}$ ). The criterion for the convergence of the self-consistent cycles was fixed to $10^{-5} \mathrm{eV}$. Geometry optimizations were performed using a conjugate-gradient algorithm and convergence criterion on forces of $0.02 \mathrm{eV} . \AA^{-1}$. In addition to the adsorbate species, the two upper atomic layers of the slab were allowed relaxing for the (100) and (110) surface models (asymmetric models, see below) whereas the full slab was relaxed for the (111) surface model. Dipolar correction along the $\mathrm{z}$ axis was found to have no impact on both optimized structure and energies, and was subsequently omitted. Vibration analysis were performed using the finite difference method by displacing each atom by $0.01 \AA$ in each direction. The harmonic frequencies of adsorbed species were used to derive the vibrational partition function and calculate adsorption enthapies and entropies, as described by Larmier et al. ${ }^{6}$

Models. We used the models for the $\gamma$-alumina surface developed by Digne et al. ${ }^{15,16}$ based on a non-spinel bulk structure ${ }^{17}$. 
The (100) surface model used in the present study consists of a triperiodic cell, the size of which is $16.8 \times 11.1 \times 28.0 \AA^{3}$, occupied by a $6.0 \AA$ wide alumina slab (normal to the $\mathrm{O}_{\mathrm{z}}$ axis) surmounted by a $22 \AA$ wide vacuum slab. The Brillouin zone integration is performed on a $1 \times 2 \times 1 \mathrm{k}$-points grid mesh. The $(110)$ surface model is $16.1 \times 16.8 \times 28.0 \AA^{3}$ wide, occupied by a $6.0 \AA$ thick alumina slab (normal to the $\mathrm{Oz}$ axis), representing four alumina layers, surmounted by a $22 \AA$ wide vacuum slab. The Brillouin zone integration is performed on a $1 \times 1 \times 1$ kpoints grid mesh. Both surfaces are considered in a dehydrated or hydrated state, with $\mathrm{OH}$-coverage increasing from 0 to $15 \mathrm{OH} \cdot \mathrm{nm}^{-2}$. The hydrated models were constructed by adsorbing water molecules and optimizing the structure, as performed by Digne et al ${ }^{15,16}$. For the (100) surface, no significant difference with their work has been found in terms of geometries (slight energy differences, due to different parameters in the calculations and cell size). For the (110) termination, a surface reconstruction leading to a strong stabilization for $\mathrm{OH}$ coverage superior or equal to $9.0 \mathrm{OH} \cdot \mathrm{nm}^{-2}$, as proposed by Wischert et al. ${ }^{18}$ was also taken into account. The differences between these surface models are detailed in supporting information S3. The (111) surface models employed are exactly the same (in terms of initial geometry) as in ref. ${ }^{16}$. The slab is symmetric (hydroxylated on both surfaces) with a vacuum thickness of $12 \AA$ between slabs. For reasons explained in ref. ${ }^{16}$, the (111) surface is considered at three hydroxyl coverage, which are 9.8, 12.3 and 14.7 $\mathrm{OH} \cdot \mathrm{nm}^{-2}$. In the operating conditions experimentally concerned here (dehydration temperature $<600^{\circ} \mathrm{C}$ ), lower hydroxyl contents are not expected at this very hydrophilic surface.

Calculation of the hydroxyl coverage. The total $\mathrm{OH}$ coverage of the surface under given temperature and water partial pressure, taking into account the different possible facets of the alumina, was calculated according to a procedure inspired from Joubert et al. ${ }^{39,40}$ and reported elsewhere ${ }^{6}$. 
We consider herein that the whole surface of each crystallographic plane ((100), (110) or (111)) is composed of $\mathrm{N}$ elementary surface cells. Each cell behaves as a complex that can bind water molecules: from 0 to 6 for the (110) crystallographic plane, 0 to 4 for the (100) plane, 4 to 6 for the (111). Let us define the successive adsorption reactions (Si) and global adsorption reactions $(\mathbf{G i})$ :

$$
\begin{aligned}
A_{i-1}+\mathrm{H}_{2} \mathrm{O}_{(g)}=A_{i} & (\mathbf{S i}) \\
i \mathrm{H}_{2} \mathrm{O}_{(g)}+A_{0}=A_{i} & (\mathbf{G} \boldsymbol{i})
\end{aligned}
$$

where $A_{i}$ stand for the surface cell with $i$ water molecules attached $(0 \leq i \leq 4$ for the (100) surface, $0 \leq i \leq 6$ for the (110) surface, $4 \leq i \leq 6$ for the (111) surface). Each model $A_{i}$ entails a given $\mathrm{OH}$ coverage $q_{i,(100)} q_{i,(110)}$ or $q_{i,(111)}$. The associated thermodynamic constants are noted $K_{i}^{0}$ and $B_{i}^{0}$. For each of these reactions, standard enthalpies and entropies have been calculated using DFT. The results at $25{ }^{\circ} \mathrm{C}$ for reactions $(\mathbf{S i})$ are reported in Supporting Information S4. These values have a very small temperature dependence over the range 0 to $750{ }^{\circ} \mathrm{C}$. For this reason, the value at $25^{\circ} \mathrm{C}$ has been employed on the whole temperature range. From these data, reaction constants can be calculated. The following equations lead to the values of the proportions $\boldsymbol{x}_{i}$ of cells occupied by $i$ water molecules, as a function of the temperature, for a given water partial pressure $P_{\mathrm{H}_{2} \mathrm{O}}$ at equilibrium.

$$
\begin{gathered}
K_{i}=\exp \left(-\frac{\Delta_{a d s} H-T \Delta_{a d s} S}{R T}\right)=\frac{x_{i}}{x_{i-1} P_{H_{2} O} \mathrm{O}} \\
B_{i}^{0}=\frac{x_{i}}{x_{0}\left(P_{\mathrm{H}_{2} O}\right)^{i}} \\
B_{i}^{0}=\prod_{n=1}^{i} K_{n} \\
\sum_{i=0}^{i_{\max }} x_{i}=1 \\
x_{i}=\frac{B_{i}^{0}\left(P_{H_{2} O}\right)^{i}}{\sum_{i=0}^{i_{m a x}} B_{i}^{0}\left(P_{H_{2} O}\right)^{i}} \\
x_{0}=\frac{1}{\sum_{i=0}^{i_{m a x}} B_{i}^{0}\left(P_{H_{2} O}\right)^{i}}
\end{gathered}
$$


Finally, the total $\mathrm{OH}$ coverage $\mathrm{q}_{D F T}$ (in $\mathrm{OH} . \mathrm{nm}^{-2}$ ) is calculated by the following formula (eq. 36):

$$
q_{D F T}=X_{(100)} \sum_{i=1}^{4} q_{i,(100)} x_{i,(100)}+X_{(110)} \sum_{i=1}^{6} q_{i,(110)} x_{i,(110)}+X_{(111)} \sum_{i=1}^{2} q_{i,(111)} x_{i,(111)}
$$

where $X_{(100)}, X_{(110)}$ and $X_{(111)}$ are the proportions of facets (100), (110) and (111), respectively. We considered the ratio of these different facets to be $20 \%, 70 \%$ and $10 \%$, respectively.

\section{RESULTS AND DISCUSSION}

\subsection{TPD experiments.}

The results of the "classical" (non-interupted) TPD are shown on Figure 4. Note that the $\mathrm{OH}$ concentration is not zero at the end of the experiment, because of the 3 hours plateau at $600^{\circ} \mathrm{C}$ necessary to reach the reference state (see Figure 2).

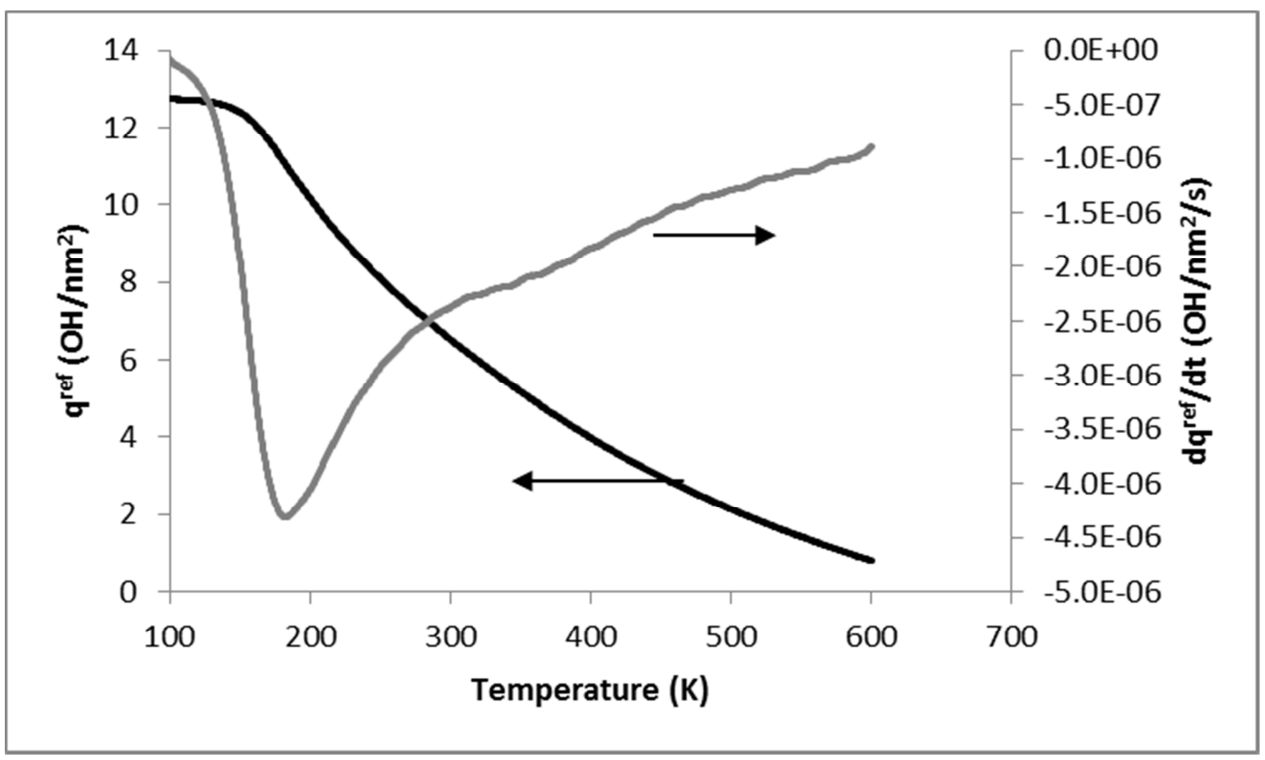

Figure 4: Classical TPD at $1 \mathrm{~Pa}$ of water. 
The $\mathrm{OH}$ concentration decreases monotonously with temperature, in agreement with the results of Men et $\mathrm{al}^{22}$, and the desorption rate shows only one minimum at $180^{\circ} \mathrm{C}$. This continuous distribution is less discrete than the TPD profiles simulated by Joubert et al. ${ }^{39}$, who attributed this discrepancy to an underestimation of the surface heterogeneity by the DFT model. Also, the desorption rate is not zero at the end of the experiment $\left(600^{\circ} \mathrm{C}\right)$, confirming that all the $\mathrm{OH}$ have not yet desorbed from the surface.

The thermogram of the interrupted TPD at $1 \mathrm{~Pa}$ of water is presented on Figure 5. It can be seen that the desorption kinetic is substantially slower during the temperature-constant steps. Consequently, the signal is not stabilized even after $4 \mathrm{~h}$ at constant temperature. This effect has been noticed for all water partial pressures.

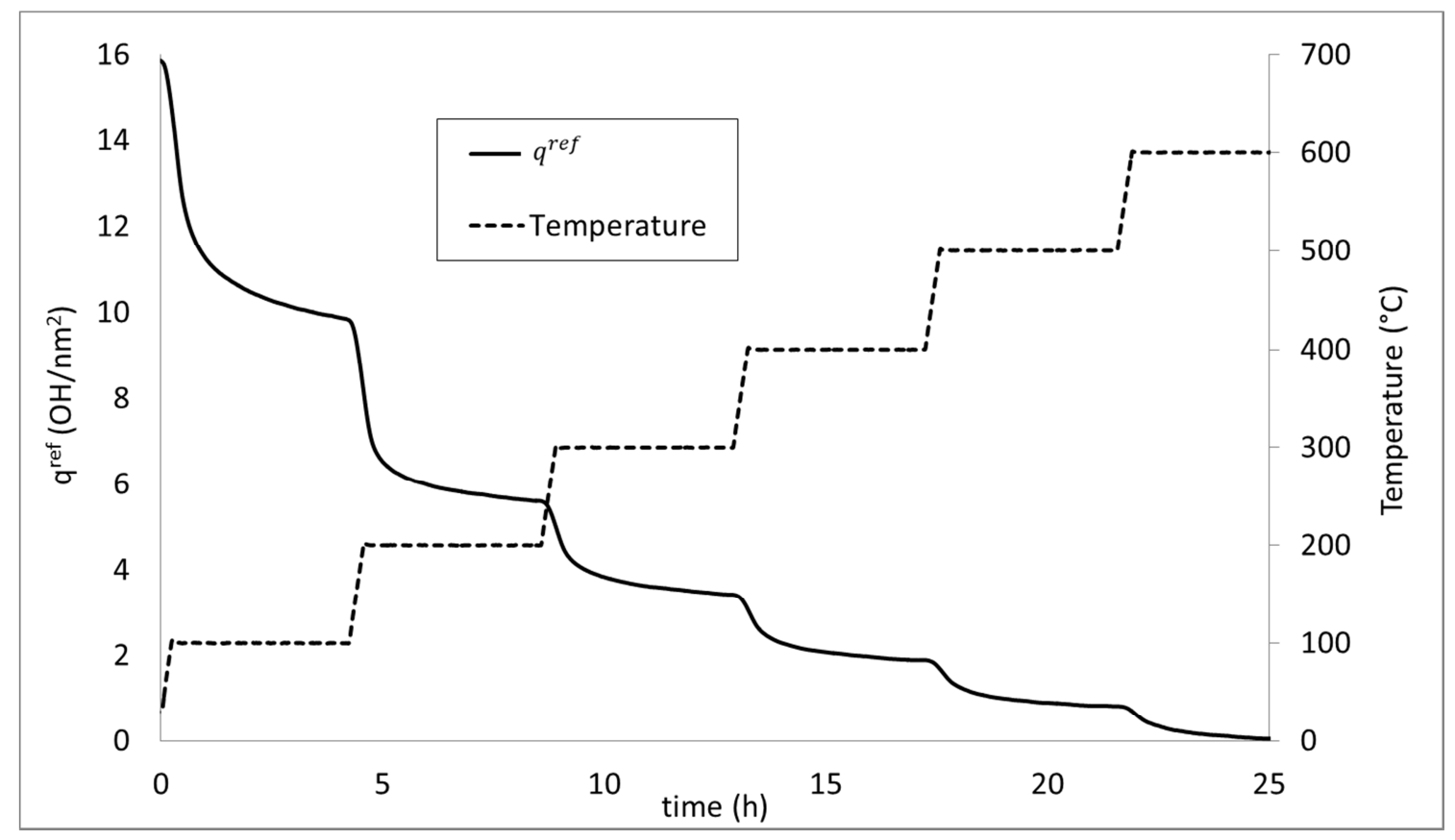

Figure 5: Interrupted TPD at $1 \mathrm{~Pa}$ of water.

In order to evaluate the deviation from equilibrium at the end of each temperature plateau, comparison between adsorption and desorption experiments have been performed for a water partial pressure of $1400 \mathrm{~Pa}$. As a reminder, for desorption experiments, the saturated sample is 
heated from $100^{\circ} \mathrm{C}$ to $600^{\circ} \mathrm{C}$ by steps of $100^{\circ} \mathrm{C}$ (as seen on Figure 5) at a water pressure of $1400 \mathrm{~Pa}$, whereas for adsorption experiments, the sample is first heated to $600^{\circ} \mathrm{C}$ (to dehydrate the surface), then cooled down to $100^{\circ} \mathrm{C}$ by steps of $100^{\circ} \mathrm{C}$ under a water pressure of $1400 \mathrm{~Pa}$, and finally heated at $600^{\circ} \mathrm{C}$ under a water pressure of $1 \mathrm{~Pa}$ to obtain the dehydrated reference state.

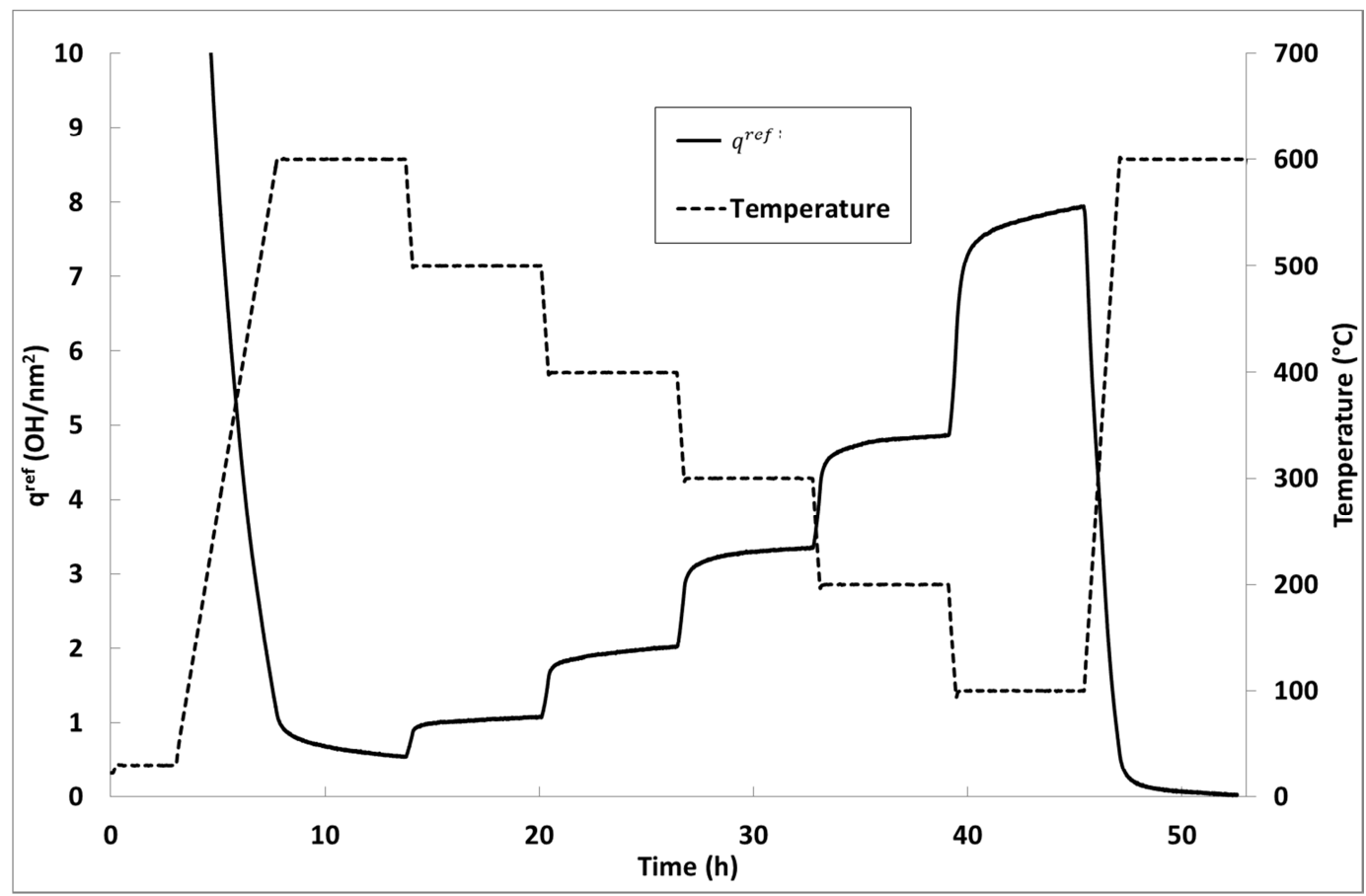

Figure 6: Thermogram for the adsorption experiment at $1400 \mathrm{~Pa}$ of water .

As can be seen on the adsorption thermogram (Figure 6), the time necessary to stabilize the $\mathrm{OH}$ concentration during the constant temperature steps is far from negligible, particularly at $100^{\circ} \mathrm{C}$. From the comparison of the adsorption and desorption kinetics in the same conditions (1400 $\mathrm{Pa}$ of water and $300^{\circ} \mathrm{C}$, Figure 7 ), it can be concluded that more than an hour is necessary to stabilize the signal, both in the adsorption and in the desorption mode. Moreover, the two signals do not converge to the same value: the $\mathrm{OH}$ coverage is substantially higher on the surfaces obtained by desorption, showing that the thermodynamic equilibrium is clearly not reached. 


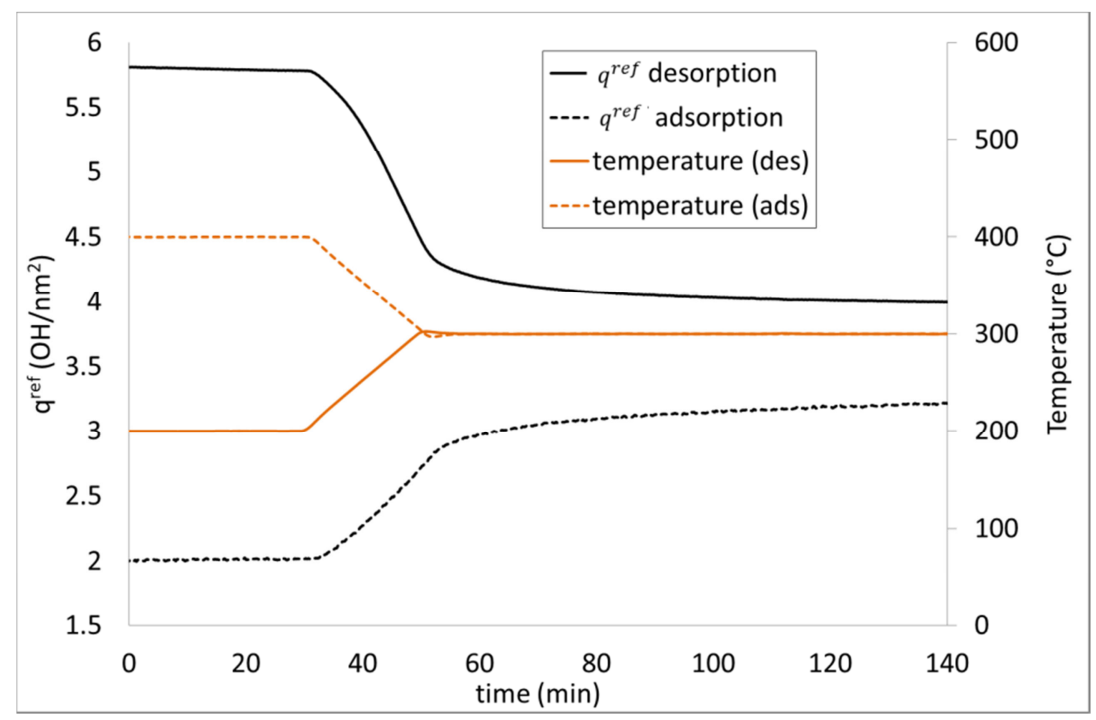

Figure 7 : adsorption and desorption thermogram at $1400 \mathrm{~Pa}$ of water and $300^{\circ} \mathrm{C}$ (the time scale is corrected so that the temperature plateau is reached at $\mathrm{t}=50 \mathrm{~min}$ )

A possible explanation would be an evolution of the alumina surface during the thermal treatment. Indeed, for the adsorption experiment, the sample is first heated at $600^{\circ} \mathrm{C}$,which is not the case for the desorption experiments. To check if the thermal history could have any influence on the sample surface, successive adsorption/desorption experiments have been carried-out by cycling the temperature from $30^{\circ} \mathrm{C}$ to $600^{\circ} \mathrm{C}$ (desorption) and back to $30^{\circ} \mathrm{C}$ (adsorption), always keeping the water partial pressure of water at $1400 \mathrm{~Pa}$. The results can be seen in Supporting Information S5. The data from thermal cycles fit perfectly with data from single desorption and adsorption experiments. Moreover, the specific surface area of the sample after 5 cycles is $207 \pm 11 \mathrm{~m}^{2} \mathrm{~g}^{-1}$, that is to say very close to the initial value $\left(228 \pm 12 \mathrm{~m}^{2}\right.$ $\left.\mathrm{g}^{-1}\right)$. The alumina surface can therefore be considered as unaltered by the hydrothermal cycles. The good reproducibility of these experiments also points out the excellent precision of the experimental measurements. Thus, the difference between adsorption and desorption behaviors cannot be assigned to a surface reconstruction. At this stage, the offset between 
adsorption and desorption results might be explained by the higher activation needed for desorption as compared to adsorption.

From these preliminary experiments, it can be concluded that a large set of interaction strength between water and the alumina surface is possible: both easy-to-desorb hydroxyls, that can be removed at relatively low temperature, and hydroxyls strongly bonded to the surface, whose kinetic of desorption is negligible at low temperature, are present at the surface. In other words, the surface of the sample is highly heterogeneous, constituted of adsorption sites of different types and strength (in agreement with previous IR and DFT studies, see Introduction). As seen in the experimental and methods section, this kind of surface can be represented by an Energy Distribution Function (EDF), that relates the relative frequencies of surface sites associated to a given adsorption energy.

\subsection{Evaluation of the EDF.}

To evaluate the EDF from TPD experiments, the procedure described in the experimental section was applied. First, the evolution of $\mathrm{A}_{\mathrm{d}}$ (the pre-exponential factor of the desorption kinetic parameter) with the adsorption enthalpy was estimated, by fitting experimental and simulated interrupted TPD at different temperatures, as described on Figure 4. The evolution of $\mathrm{A}_{\mathrm{d}}$ with $\Delta_{\mathrm{ads}} \mathrm{H}$ is presented on Figure 8-a. A linear relationship between the logarithm of the pre-exponential factor and the adsorption enthalpy is observed. That is typical of the “compensation effect”, observed for many rate-limited processes. ${ }^{26,28,29}$

Using this linear function, the desorption kinetics at each plateau of the interrupted TPD were simulated and are compared with experimental results on Figure 8-b. The experimental points are very well simulated by the model for all temperatures, showing the good precision of the estimated parameters. 


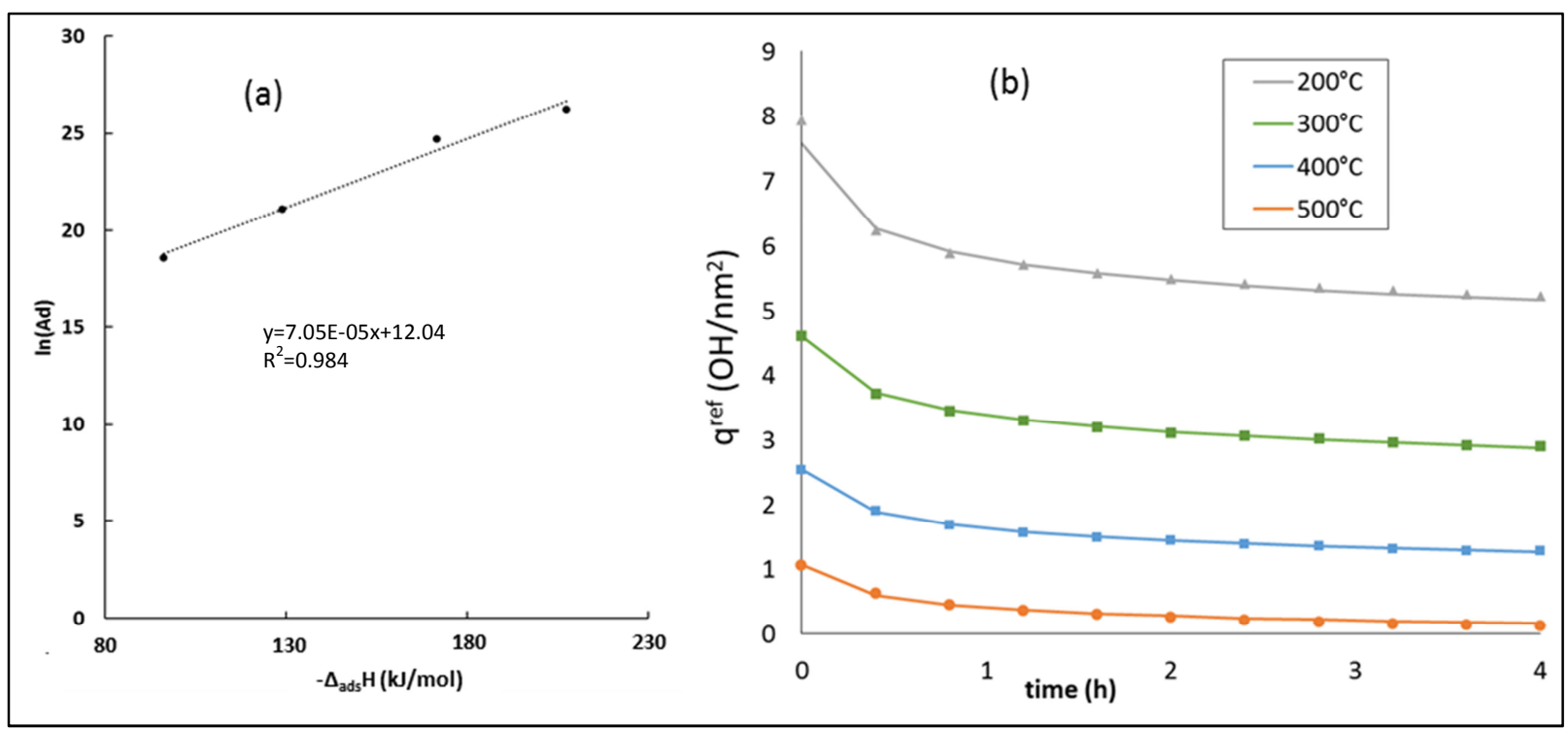

Figure 8 : (a): Evolution of pre-exponential term $A_{d}$ with adsorption enthalpy ; (b): Kinetic desorption experiments (points) at $1 \mathrm{~Pa}$ of water vs. simulations (lines) using correlation of

Figure 8 -a (the time scale is corrected so that all the temperature plateaus start at $\mathrm{t}=0$ ).

As $\mathrm{A}_{\mathrm{d}}$ can now be calculated for any value of $\Delta_{\mathrm{ads}} \mathrm{H}$, it is thus possible to use eq. 19 to determine the EDF of the sample. The curve is presented in black on Figure 9.

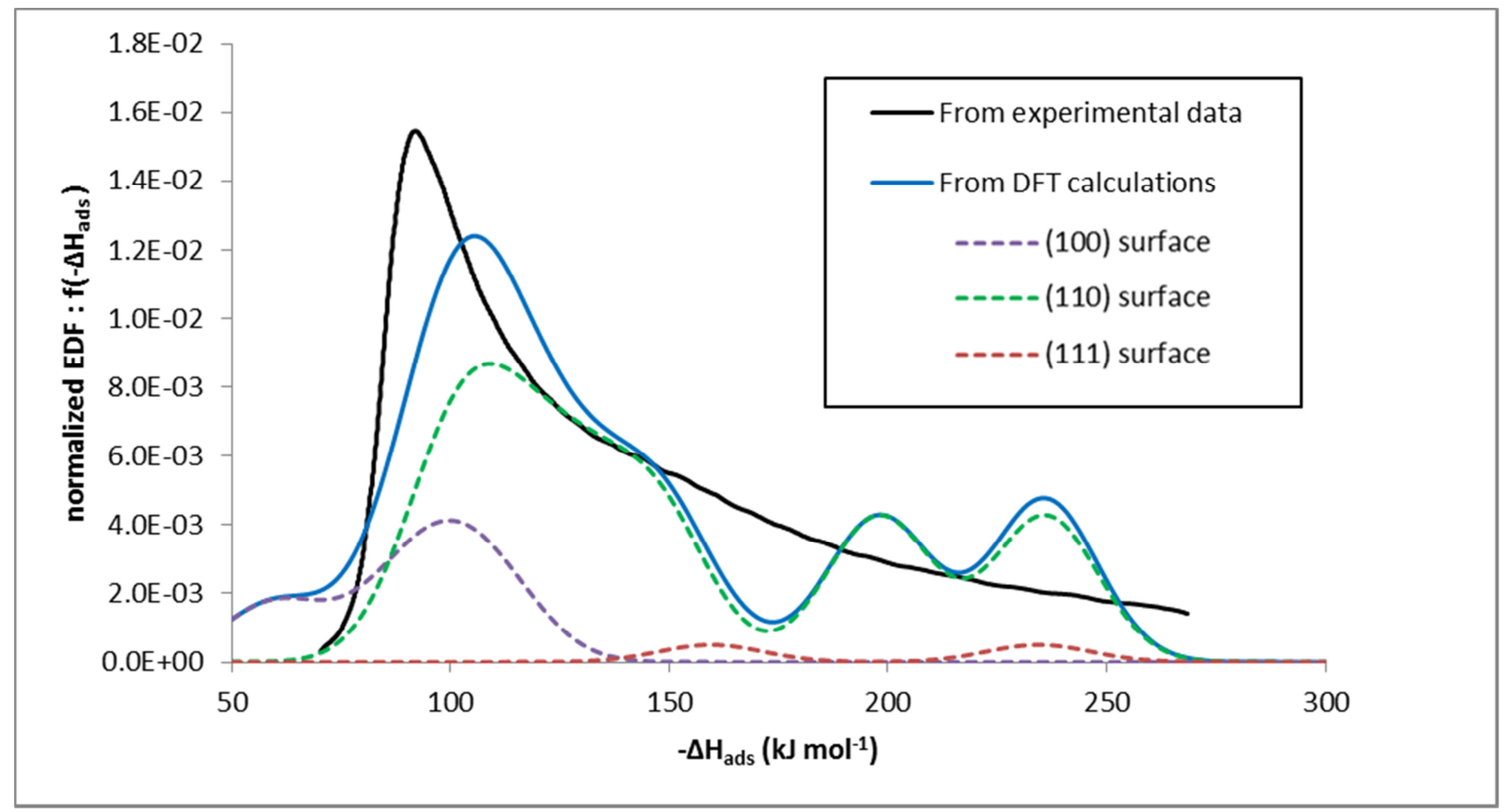

Figure 9: Energy Distribution Function (EDF) of the sample, obtained from experimental and DFT data, with models inspired from Digne et al. ${ }^{15,16}$ for the (110) surface. In the latter case, the individual contributions from the three main crystallographic surfaces is shown. 
As expected, the EDF has the same shape as the desorption kinetic shown on Figure 4. The maximum of the curve (i.e. the more frequent adsorption enthalpy) is around $-100 \mathrm{~kJ} / \mathrm{mol}$. The adsorption enthalpies vary from $-70 \mathrm{~kJ} / \mathrm{mol}$ to $-270 \mathrm{~kJ} / \mathrm{mol}$ in very good agreement with the calorimetric data reported in literature ${ }^{23,24}$. One has to keep in mind that, as evaluated by chimiometry in section 2.4., residual hydroxyls $\left(1.7 \mathrm{OH} / \mathrm{nm}^{2}\right)$ with higher adsorption enthalpies are still present on the surface at the end of the experiment.

It is also insightful to compare the enthalpy values provided by the EDF with DFT calculations (Supporting Information S4). The simulated adsorption enthalpies vary from -54 to $-236 \mathrm{~kJ} / \mathrm{mol}$, which coincides with the interval of values given by the EDF (-70 to -270 $\mathrm{kJ} / \mathrm{mol}$ ). To go further in the comparison, simulated EDF was obtained from DFT calculations by considering a Gaussian broadening $(\sigma=17 \mathrm{~kJ} / \mathrm{mol})$ starting from the discrete values reported in Supporting Information S4, taking into account a 20\%:70\%:10\% proportion for the (100):(110):(111) facets.

We found a much better agreement of the EDF deduced from experiments with the DFT calculations starting from the model of Digne et al. ${ }^{15,16}$ rather than from the models of Wischert et al. ${ }^{18}$ for the (110) surface. The latter consider a local surface reconstruction leading to more stable structures. It is possible that this reconstruction needs to overcome some kinetic limitations that are not overcome in the present experimental approach. As a consequence, we will mainly report in the manuscript deductions made from the model of Digne et al. ${ }^{15,16}$ whereas the one obtained with models similar to Wischert et al. ${ }^{18}$ are reported in Supporting Information S6. The main maximum of the EDF is shifted by $14 \mathrm{~kJ}^{\mathrm{mol}}{ }^{-1}$ as compared to the EDF deduced from thermogravimetric studies, which is typical of the uncertainty of the DFT calculations, so the agreement in this enthalpy region is very satisfactory. This main peak close to $-\Delta_{\text {ads }} \mathrm{H}=100 \mathrm{~kJ}^{\mathrm{mol}}{ }^{-1}$ is due to both the (100) and (110) 
surfaces (see the decomposition of the EDF obtained from DFT data in Figure 9). Also, the same shoulder is obtained from experimental and DFT data, close to $150 \mathrm{~kJ} \cdot \mathrm{mol}^{-1}$. It is mainly due to the (110) surface and also to part of the (111) surface. However, the shape of the DFT EDF curve is too much structured between 170 and $250 \mathrm{~kJ} \cdot \mathrm{mol}^{-1}$. From DFT calculations, this zone is mainly assigned to the (110) surface and in a minor extent to the (111) surface. This is in line with previous observations from Joubert et al. ${ }^{39}$ when they compared their simulated TPD profiles for the (110) surface with experiments. Note that considering the model from Wischert et al. (Supporting information S6) does not bring significant improvement of the comparison in this zone, while decreasing the agreement in the $50-170 \mathrm{~kJ}^{\mathrm{mol}}{ }^{-1}$ zone.

\subsection{Simulation of the adsorption isotherms using the EDF.}

Validation of the EDF estimation procedure has been carried out by comparing experimental and simulated adsorption equilibrium data. To simulate adsorption isotherms, eq. 6 has been numerically integrated using the trapezoidal rule. The entropy change due to water adsorption $\Delta_{\text {ads }} S$ is assumed to be independent of coverage. According to DFT calculations, $\Delta_{\text {ads }} S$ varies between -143 and $-186 \mathrm{~J} / \mathrm{mol} / \mathrm{K}$ (Supporting Information S4). Simulations were therefore conducted using these two extreme values to analyze the sensitivity of this parameter. The results are presented on Figure 10. 


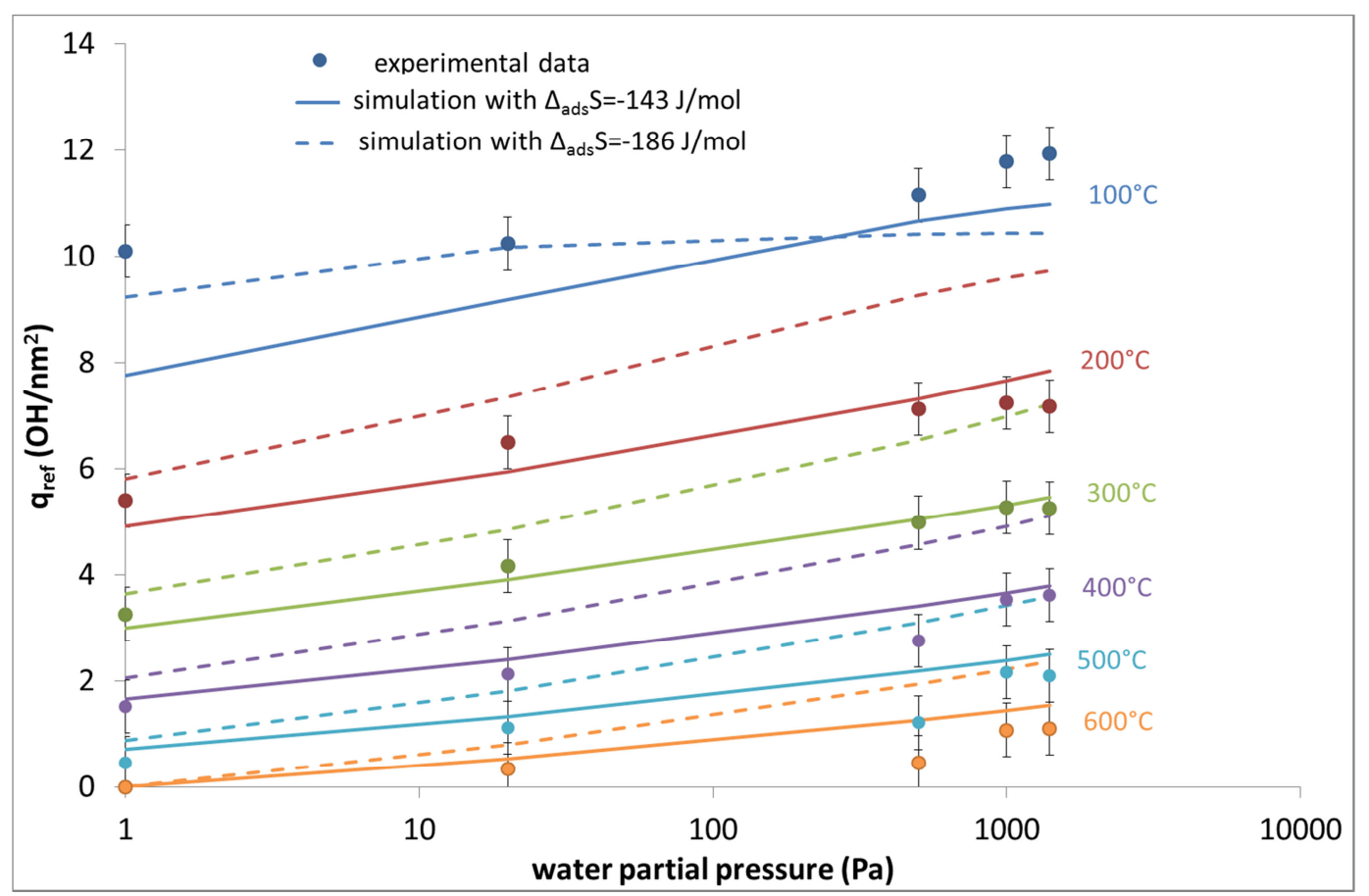

Figure 10: Simulation of adsorption isotherms (lines) compared to experimental data (points), starting from the EDF (extracted from experimental data), using different adsorption entropies.

As one can see, a very good agreement between simulated and experimental data is achieved for $\Delta_{\mathrm{ads}} \mathrm{S}=-186 \mathrm{~J} \cdot \mathrm{mol}^{-1} \cdot \mathrm{K}^{-1}$. This value is very close to the gas phase standard molar entropy of water at $25^{\circ} \mathrm{C}\left(188.7 \mathrm{~J} \cdot \mathrm{mol}^{-1} \cdot \mathrm{K}^{-1}\right)$, confirming that the translational and rotational motion of the hydroxyl groups on the surface is strongly hindered.

The good agreement between simulations and experiments shown on Figure 10 validates the EDF estimation procedure and consequently the assumptions on which it relies: the desorption (activation) step is a kinetically limited process. At a given activation temperature, some of the strongly bonded hydroxyl groups remain on the surface even though, from thermodynamic equilibrium considerations, they should desorbed. The practical consequence is that the surface state of a thermally activated a $\gamma$-alumina depends not only on temperature but also on the gas phase water partial pressure (except for very low partial pressures for which the readsorption kinetic can be considered as negligible) and, just as important, on the whole dynamic of the hydrothermal treatment (duration, temperature program). The EDF is in 
fact a very efficient tool to predict the surface coverage depending on the hydrothermal history of the sample, as can be seen on Figure 11, where the simulated surface coverage for different thermal treatments under $1 \mathrm{~Pa}$ of water is depicted.

The initial EDF corresponds to the maximum $\mathrm{OH}$ coverage after saturation of the sample at ambient condition and a first desorption step at $30^{\circ} \mathrm{C}$ and $10 \mathrm{~h}$. The reference state is the minimum coverage of the sample, at $600^{\circ} \mathrm{C}$ and $1 \mathrm{~Pa}$ of water. From the initial EDF, a temperature rise from $100^{\circ} \mathrm{C}$ to $300^{\circ} \mathrm{C}$ at $5{ }^{\circ} \mathrm{C} \cdot \mathrm{min}^{-1}$ yields a new distribution function : for $\Delta_{\mathrm{ads}} \mathrm{H}<120 \mathrm{~kJ} \cdot \mathrm{mol}^{-1}$, all the sites are empty ; for $120<-\Delta_{\mathrm{ads}} \mathrm{H}<150 \mathrm{~kJ} \cdot \mathrm{mol}^{-1}$, the sites are partially filled ; for $150 \mathrm{~kJ} \cdot \mathrm{mol}^{-1}<-\Delta_{\mathrm{ads}} \mathrm{H}$, all the sites are still saturated. Keeping the sample at $300^{\circ} \mathrm{C}$ for one hour results in further desorption of the hydroxyls. Comparing this final curve (obtained by simulating desorption experiments) with the equilibrium coverage (obtained from equilibrium calculations) at $300^{\circ} \mathrm{C}$ shows that after $1 \mathrm{~h}$ at $300^{\circ} \mathrm{C}$ the surface has not yet reached the thermodynamic equilibrium.

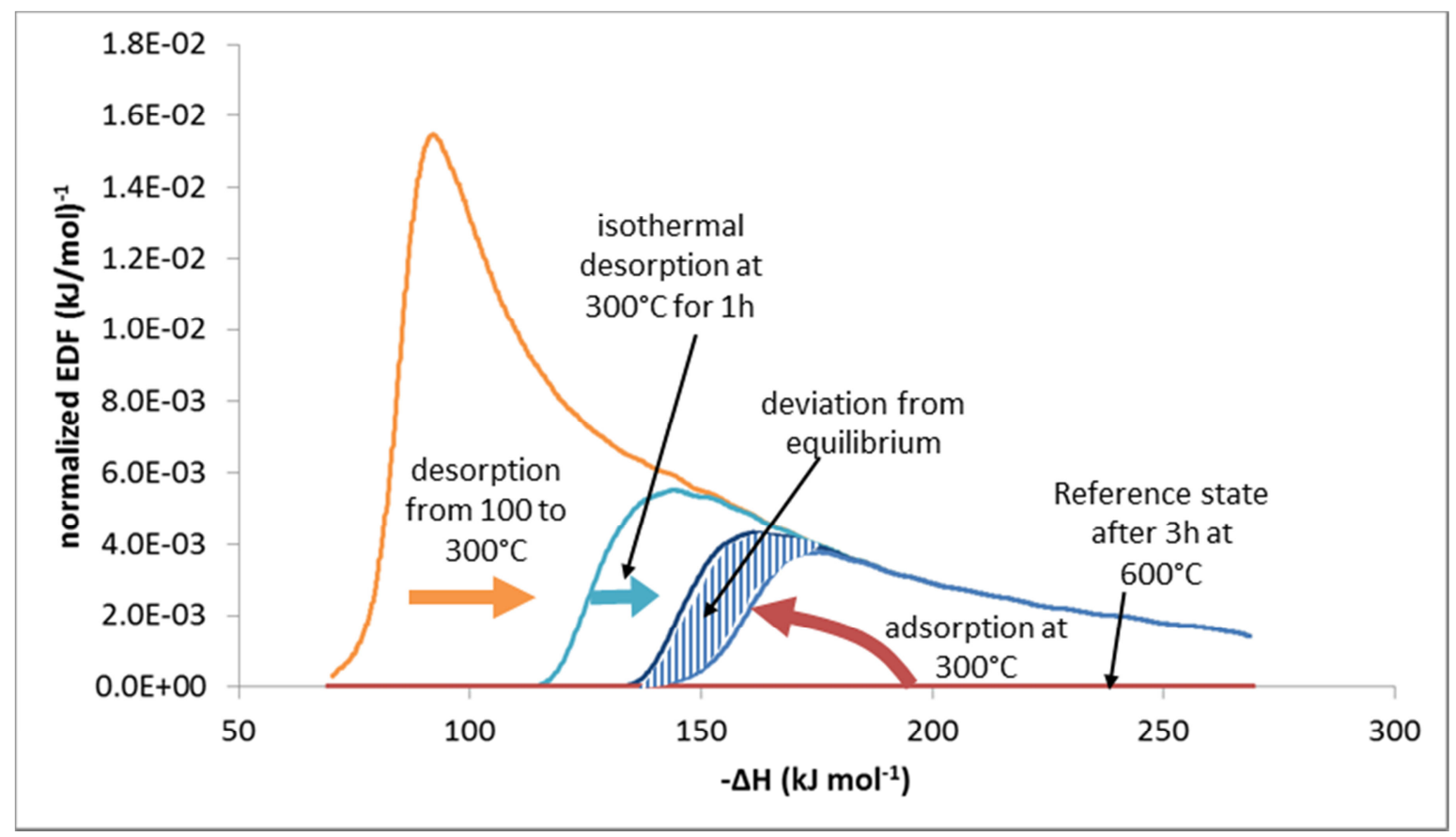

Figure 11: Evolution of surface coverage at $1 \mathrm{~Pa}$ for different hydrothermal treatments 


\subsection{Simulation of the adsorption isotherms using DFT calculations.}

A comparison between the amount of $\mathrm{OH}$ groups deduced for each temperature and water partial pressure from DFT calculations and the experimental data at equilibrium is presented in Figure 12. Regarding DFT results, they relate to the (110) surface model deduced from Digne et al. The trends obtained with the model of Wischert et al. are reported in supporting information S7.

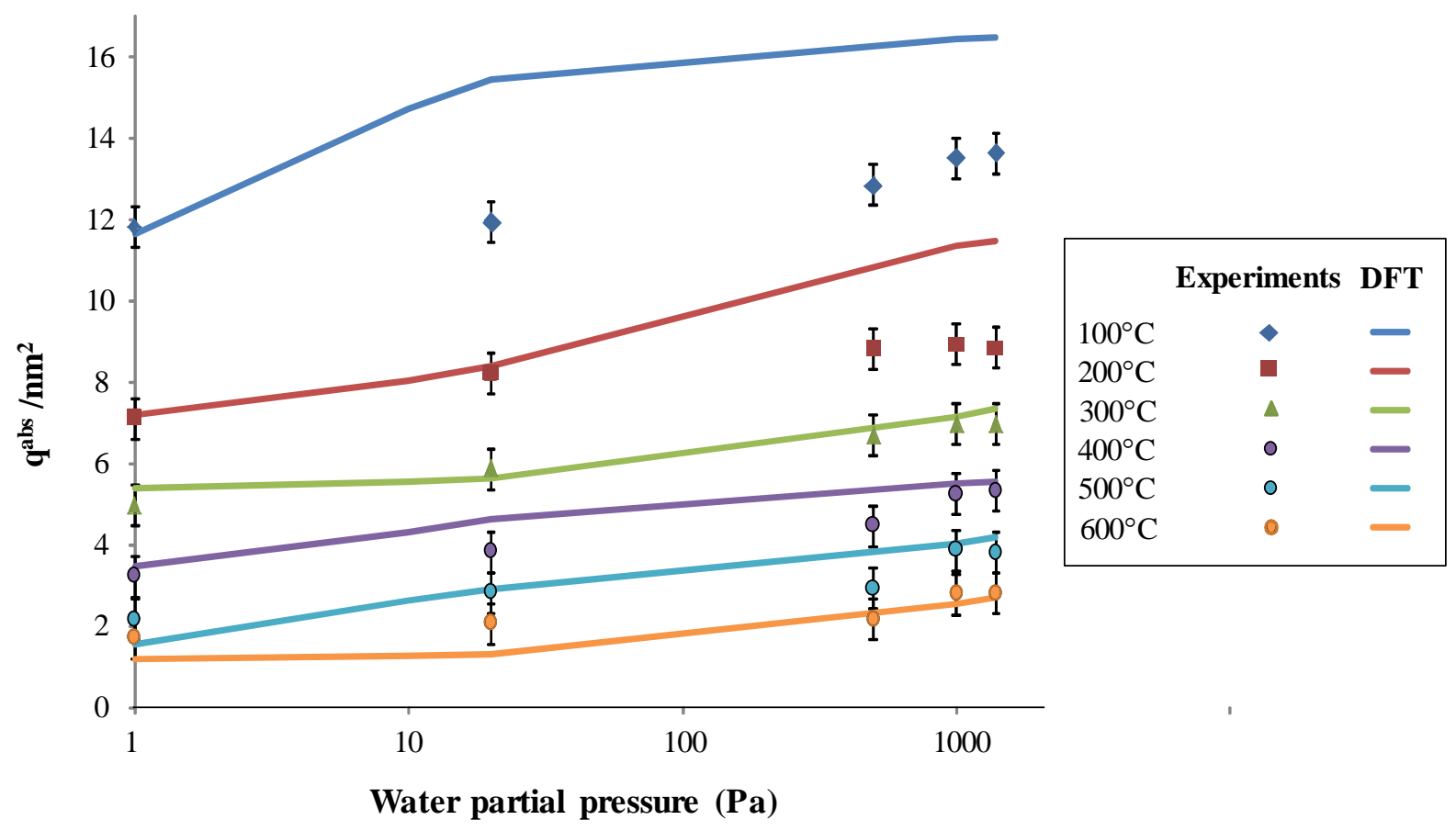

Figure 12: Comparison between experimental adsorption isotherms and DFT calculations (Digne et al. model).

The agreement between experiments and DFT is excellent for temperatures higher than $200^{\circ} \mathrm{C}$. At $200^{\circ} \mathrm{C}$, it is also excellent for water pressures up to $20 \mathrm{~Pa}$. This can be seen as a consequence of the good agreement between DFT and modeled EDF curves. For higher water pressures at $200^{\circ} \mathrm{C}$ and for $100^{\circ} \mathrm{C}$, the DFT model overestimates the amount of adsorbed water, which can be tentatively assigned to a kinetic limitation for reaching the highest coverage, with steric hindrance for water adsorption on already strongly hydroxylated 
surfaces. Such a kinetic limitation is also susceptible to be the highest at low temperatures as observed here. Another explanation could be the shift of the DFT and modeled EDF, with slightly too strong interaction as given by DFT. A last explanation could be found in adsorption entropy values, often calculated by DFT as higher than $-186 \mathrm{~J} \cdot \mathrm{K}^{-1} \cdot \mathrm{mol}^{-1}$, leading to higher adsorbed amounts. The agreement between the DFT adsorption isotherms obtained with the models inspired from Wischert et al. and experimental results is poor at most temperatures and water partial pressures (supporting information S7) except at $100^{\circ} \mathrm{C}$ where it is better than with the models inspired from Digne et al.

To conclude, thanks to the model of Digne et al., accurate predictions of the temperature and pressure dependence of the hydroxyl coverage can be reached, provided this coverage does not exceed $8 \mathrm{OH} . \mathrm{nm}^{-2}$ on the whole alumina particles (in practice, for temperatures higher than $200^{\circ} \mathrm{C}$ ). This is the case for most practical use of the solid, in particular when employed as catalyst support for reforming or hydrotreating purposes ${ }^{3}$. Entropic and kinetic reasons might be at the origin for discrepancies at higher coverage. Thus, a direct link can be established between the nanoscale hydration/dehydration phenomena investigated in references 15-16 and the present macroscopic observations.

\section{CONCLUSIONS AND PERSPECTIVES}

In this work, a detailed set of experimental data for water adsorption on $\gamma$-alumina has been acquired using a thermogravimetric equipment. By comparing desorption experiments with equilibrium data, it was demonstrated that thermal activation classically applied before catalytic tests is a kinetically limited process, i.e. that the surface hydroxyl coverage is dependent not only on the final temperature but also on the entire hydrothermal history of the 
sample. DFT calculations were performed to give an atomic scale insight in the energetic data obtained.

An Energy Distribution Function (EDF) has been estimated from classical and interrupted TPD experiments with temperatures going up to $600^{\circ} \mathrm{C}$, yielding the hydroxyl adsorption enthalpy distribution for the given $\gamma$-alumina sample. The enthalpies range from -270 to -100 $\mathrm{kJ} . \mathrm{mol}^{-1}$, in good agreement with DFT calculations. A first attempt to simulate the EDF, i.e. a continuous function, with a DFT model, which yields by nature discrete energy values, has been proposed, by attributing to each adsorption enthalpy a common Gaussian behavior. Starting from alumina surface models proposed in the past, a good agreement is found between experimental and DFT EDF for $50<-\Delta_{\mathrm{ads}} \mathrm{H}<170 \mathrm{~kJ} / \mathrm{mol}$, provided no surface reconstruction is considered by DFT for the (110) facet, which indicates that such reconstructions probably require barriers to be overcome, which is not the case in the present experimental conditions. In the high enthalpy range $\left(-\Delta_{\mathrm{ads}} \mathrm{H}>170 \mathrm{~kJ} / \mathrm{mol}\right)$, the simulated EDF still display several optima, whereas the experimental EDF curve is smooth. Further work should therefore be conducted to better understand the link between the discrete DFT data and the continuous EDF function. Nonetheless, the ability for the atomic-scale model to simulate the macroscopic adsorption properties allows to link the chemical nature of the sites to the global properties of the surface, mainly driven by the (100) and the (110) orientations.

The capacity of the EDF to predict totally independent adsorption equilibrium data was tested with success, showing both the validity of the estimation methodology and the capacity of the EDF to simulate the surface water coverage for very different hydrothermal treatments. The comparison with DFT calculated hydroxyl contents is very good for temperatures above $200^{\circ} \mathrm{C}$, although DFT overestimates the $\mathrm{OH}$ coverage above $8 \mathrm{OH} \cdot \mathrm{nm}^{-2}$ (for temperatures lower than $\left.200^{\circ} \mathrm{C}\right)$. 
Evaluating the EDF of alumina nanoparticles obtained by different synthesis methods should be very useful to better understand the relationship between the surface properties, the particles morphology and the nature of the sites at the atomic scale.

\section{ASSOCIATED CONTENT}

Supporting Information file.

\section{AUTHOR INFORMATIONS}

\section{Corresponding author}

* Email: elsa.jolimaitre@ifpen.fr. Tel : 0033437702513

\section{Acknowledgment}

The authors thank Pascal Raybaud (IFP Energies nouvelles) and Christophe Copéret (ETH Zürich) for fruitful discussions. K.L. thanks ETH Zurich for funding.

\section{Notes}

The authors declare no competing financial interest.

\section{REFERENCES}

1 Euzen, P.; Raybaud, P.; Krokidis, X.; Toulhoat, H.; Loarer, J. L.; Jolivet, J.-P.; Froidefond, C. In Handbook of Porous Solids; Schüth, F., Sing, K. S. W., Weitkamp, J., Eds.; Wiley-VCH: Weinheim, 2002 
2 Busca, G. The surface of transitional aluminas: A critical review. Catal. Today 2014, $226,2-13$

3 Raybaud, P.; Costa, D.; Corral Valero, M.; Arrouvel, C.; Digne, M.; Sautet, P.; Toulhoat, H. First principles surface thermodynamics of industrial supported catalysts in working conditions. J. Phys.: Condens. Matter 2008, 20, 064235

4 Hindin, S.G., Weller, S.W. The Effect of Pretreatment on the Activity of GammaAlumina. I. Ethylene Hydrogenation. J. Phys. Chem. 1956, 60, 1501-1506.

5 Larmier, K.; Nicolle, A.; Chizallet, C.; Cadran, N.; Maury, S.; Lamic-Humblot, A.-F.; Marceau, E.; Lauron-Pernot, H. Influence of Coadsorbed Water and Alcohol Molecules on Isopropyl Alcohol Dehydration on $\gamma$-Alumina: Multiscale Modeling of Experimental Kinetic Profiles. ACS Catalysis 2016, 6, 1905-1920.

6 Larmier, K.; Chizallet, C.; Cadran, N.; Maury, S.; Abboud, J.; Lamic-Humblot, A.-F.; Marceau, E.; Lauron-Pernot, H. Mechanistic Investigation of Isopropanol Conversion on Alumina Catalysts: Location of Active Sites for Alkene/Ether Production. ACS Catalysis 2015, 5, 4423-4437.

7 Wischert, R.; Copéret, C.; Delbecq, F.; Sautet, P. Angew. Optimal Water Coverage on Alumina: A Key to Generate Lewis Acid-Base Pairs that are Reactive Towards the C[BOND]H Bond Activation of Methane. Chem. Int. Ed. 2011, 50, 3202-3205.

8 Hietala, J.; Root, A.; Knuuttila, P. The Surface Acidity of Pure and Modified Aluminas in Re/Al2O3 Metathesis Catalysts as Studied by 1H MAS NMR Spectroscopy and Its Importance in the Ethenolysis of 1,5-Cyclooctadiene. J. Catal. 1994, $150,46-55$.

9 DeCanio, E. C.; Nero, V. P.; Bruno, J. W. Identification of alcohol adsorption sites on

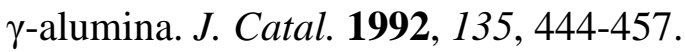


10 Delgado, M.; Delbecq, F.; Santini, C. C.; Lefebvre, F.; Norsic, S.; Putaj, P.; Sautet, P.; Basset, J.-M. Evolution of Structure and of Grafting Properties of $\gamma$-Alumina with Pretreatment Temperature. J. Phys. Chem. C 2012, 116, 834-843.

11 Knözinger, H., Ratnasamy, P. Catalytic Aluminas: Surface Models and Characterization of Surface Sites. Catal. Rev. Sci. Eng. 17, 1978, 31-70.

12 Tsyganenko, A., Filimonov, V.N. Infrared Spectra of Surface Hydroxyl Groups and Crystalline Structure of Oxides. Spectrosc. Lett. 5. 1972, 477-487.

13 Morterra, C., Chiorino, A., Ghiotti, G., Garrone, E. Surface acidity of $\eta$-alumina. Part 1.Pyridine chemisorption at room temperature. Faraday Trans. 1, 1979, 271-288.

14 Busca, G., Lorenzelli, V., Ramis, G., Willey, R.J. Surface sites on high-area spineltype metal oxides. Langmuir., 1993, 9, 1492-1499.

15 Digne, M.; Sautet, P.; Raybaud, P.; Euzen, P.; Toulhoat, H. Hydroxyl Groups on $\gamma$ Alumina Surfaces: A DFT Study. J. Catal. 2002, 211, 1-5.

16 Digne, M.; Sautet, P.; Raybaud, P.; Euzen, P.; Toulhoat, H. Use of DFT to achieve a rational understanding of acid-basic properties of $\gamma$-alumina surfaces. J. Catal. 2004, 226, 54-68.

17 Krokidis, X.; Raybaud, P.; Gobichon, A. E.; Rebours, B.; Euzen, P.; Toulhoat, H. Theoretical Study of the Dehydration Process of Boehmite to $\gamma$-Alumina. Journal of Physical Chemistry B 2001, 105, 5121-5130.

18 Wischert, R.; Laurent, P.; Copéret, C.; Delbecq, F.; Sautet, P. $\gamma$-Alumina: the essential and unexpected role of water for the structure, stability, and reactivity of "defect" sites. J. Am. Chem. Soc. 2012, 134, 14430-14449.

19 Ruthven, D.M. Adsorption of water vapour on activated alumina. I - equilibrium behavior. Canadian J. Chem. Eng. 1992, 70, 699-706.

20 Serbezov, A. Adsorption Equilibrium of Water Vapor on F-200 Activated Alumina. $J$. Chem. Eng. Data 2003, 48, 421-425. 
21 Li,G.; Xiao,P.; Webley,P. Binary adsorption equilibrium of carbon dioxide and water vapor on activated alumina. Langmuir 2009, 25, 10666-10675.

22 Men, Y.; Gnaser, H.; Ziegler, C. Adsorption/desorption studies on nanocrystalline alumina surfaces. Anal. Bioanal. Chem. 2003, 375, 912-916.

23 McHale, J.M.; Auroux, A.; Perrotta, A.J. ; Navrotsky, A. Surface Energies and Thermodynamic Phase Stability in Nanocrystalline Aluminas. Science 1997, 277, 788791.

24 Hendriksen, B. A.; Pearce, D. R.; Rudham, R. Heats of adsorption of water on $\alpha$ - and $\gamma$-alumina. J. Catal. 1972, 24, 82-87.

25 Rudzinski, W.; Everett, D. H. Adsorption of Gases on Heterogeneous Surfaces; Academic Press: London, 1992

26 Barrie, P.J. Analysis of temperature programmed desorption (TPD) data for the characterisation of catalysts containing a distribution of adsorption sites. Phys. Chem. Chem. Phys. 2008, 10, 1688-1696.

27 Eyring, H. The Activated Complex in Chemical Reactions. J. Chem. Phys. 1935, 3, 107-115.

28 Rudzinski, W. ; Panczyk, T. Kinetics of Isothermal Adsorption on Energetically Heterogeneous Solid Surfaces: A New Theoretical Description Based on the Statistical Rate Theory of Interfacial Transport. J. Phys. Chem. B., 2000, 104, 91499162.

29 Spiewak, B. E. ; Dumesic, J. A. Microcalorimetric measurements of differential heats of adsorption on reactive catalyst surfaces. Thermochim. Acta, 1996, 290, 43-53.

30 Cerofolini, G. F.; Re, N. Extracting the Energy Distribution Functions of Heterogeneous Surfaces from Their Desorption Kinetics. J. Colloid Interface Sci. 1995, $174,428-440$.

31 Bogillo, V. I.; Shkilev, V. P. Evaluation of desorption energy distributions from TPD spectra on a heterogeneous solid surface. J. Therm. Anal. Calorim. 1999, 55, 483-492. 
32 Seebauer, E. G. Quantitative extraction of continuous distributions of energy states and pre-exponential factors from thermal desorption spectra. Surf. Sci. 1994, 316, 391405.

33 Coperet, C.; Comas-Vives, A.; Conley, M. P.; Estes, D. P.; Fedorov, A.; Mougel, V.; Nagae, H.; Nunez-Zarur, F.; Zhizhko, P. A. Surface Organometallic and Coordination Chemistry toward Single-Site Heterogeneous Catalysts: Strategies, Methods, Structures, and Activities. Chem Rev 2016, 116, 323-421.

34 Perdew, J.; Burke, K.; Ernzerhof, M. Generalized Gradient Approximation Made Simple. Phys. Rev. Lett. 1996, 77, 3865-3868.

35 Grimme, S. Semiempirical GGA-type density functional constructed with a long-range dispersion correction. J. Comput. Chem. 2006, 27, 1787-1799.

36 Kresse, G.; Hafner, J. Ab initio molecular-dynamics simulation of the liquid-metalamorphous-semiconductor transition in germanium. Phys. Rev. B 1994, 49, 1425114269.

37 Kresse, G.; Furthmüller, J. Efficiency of ab-initio total energy calculations for metals and semiconductors using a plane-wave basis set. Comput. Mat. Sci. 1996, 6, 15-50.

38 Kresse, G.; Joubert, D. From ultrasoft pseudopotentials to the projector augmentedwave method. Phys. Rev. B 1999, 59, 1758-1775.

39 Joubert, J.; Fleurat-Lessard, P.; Delbecq, F.; Sautet, P. Simulating temperature programmed desorption of water on hydrated gamma-alumina from first-principles calculations. J. Phys. Chem. B 2006, 110, 7392-7395.

40 Joubert, J.; Salameh, A.; Krakoviack, V.; Delbecq, F.; Sautet, P.; Copéret, C.; Basset, J. M. Heterolytic splitting of $\mathrm{H}_{2}$ and $\mathrm{CH}_{4}$ on gamma-alumina as a structural probe for defect sites. J. Phys. Chem. B 2006, 110, 23944-23950. 
TOC image

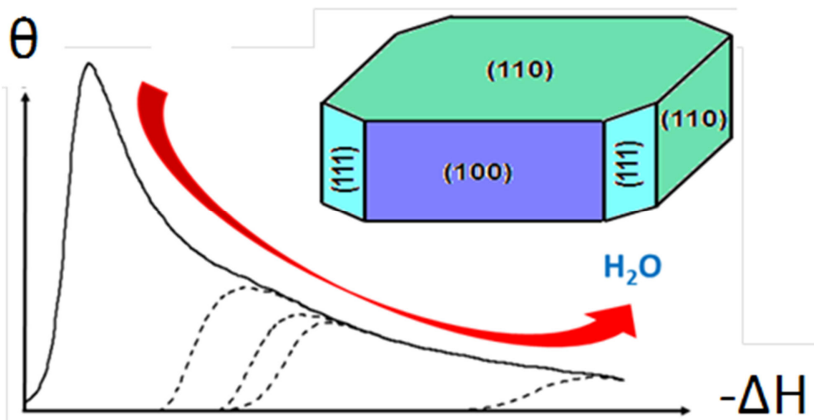

